\title{
1 A toolbox for imaging RIPK1, RIPK3 and MLKL in mouse and human cells
}

2

3 André L. Samson ${ }^{1,2 *}$, Cheree Fitzgibbon ${ }^{1}$, Komal M. Patel ${ }^{1}$, Joanne M. Hildebrand ${ }^{1,2}$, Lachlan W.

4 Whitehead $^{1,2}$, Joel S. Rimes ${ }^{1,2}$, Annette V. Jacobsen ${ }^{1,2}$, Christopher R. Horne ${ }^{1,2}$, Xavier J. Gavin ${ }^{1,2}$,

5 Samuel N. Young ${ }^{1}$, Kelly L. Rogers ${ }^{1,2}$, Edwin D. Hawkins ${ }^{1,2}$, James M. Murphy ${ }^{1,2 *}$

6

$7{ }^{1}$ Walter and Eliza Hall Institute of Medical Research, 1G Royal Parade, Parkville, VIC 3052,

8 Australia

$9 \quad{ }^{2}$ Department of Medical Biology, University of Melbourne, Parkville 3052, Australia

10

11 *Please address correspondence to samson.a@wehi.edu.au (ALS) or jamesm@wehi.edu.au (JMM)

12

13 Running title: Imaging necroptosis in mouse and human cells

14

15 Keywords: kinase, pseudokinase, cell death, programmed necrosis, fixative 
ABSTRACT

17 Necroptosis is a lytic, inflammatory cell death pathway that is dysregulated in many human pathologies. The pathway is executed by a core machinery comprising the RIPK1 and RIPK3 kinases, which assemble into necrosomes in the cytoplasm, and the terminal effector pseudokinase, MLKL. RIPK3-mediated phosphorylation of MLKL induces oligomerization and translocation to the plasma membrane where MLKL accumulates as hotspots and perturbs the lipid bilayer to cause death. The precise choreography of events in the pathway, where they occur within cells, and pathway differences between species, are of immense interest. However, they have been poorly characterized due to a dearth of validated antibodies for microscopy studies. Here, we describe a toolbox of antibodies for immunofluorescent detection of the core necroptosis effectors, RIPK1, RIPK3 and MLKL, and their phosphorylated forms, in human and mouse cells. By comparing reactivity with endogenous proteins in wild-type cells and knockout controls in basal and necroptosis-inducing conditions, we characterise the specificity of frequently-used commercial and recently-developed antibodies for detection of necroptosis signaling events. Importantly, our findings demonstrate that not all frequently-used antibodies are suitable for monitoring necroptosis by immunofluorescence microscopy, and methanol- is preferable to paraformaldehyde-fixation for robust detection of specific RIPK1, RIPK3 and MLKL signals. 


\section{INTRODUCTION}

Cell death by necroptosis is thought to have originated as an ancestral host defence mechanism, which is reflected in the breadth of pathogen-encoded proteins that inhibit the pathway ${ }^{1,2,3,4,5,6}$. In addition to reported innate immunity functions ${ }^{7,8,9}$, the dysregulation of necroptosis has been implicated in a range of pathologies, including ischemic-reperfusion injuries, such as in the kidney ${ }^{10,11}$ and heart ${ }^{12}$, and inflammatory diseases ${ }^{13,14,15,16}$, including inflammatory bowel disease ${ }^{17}$. Accordingly, there is widespread interest in therapeutically-targeting the pathway to counter human disease. Owing to the recent identification of the terminal effectors of the pathway, RIPK3 (in 2009) ${ }^{1,18,19}$ and MLKL (in 2012 $)^{20,21}$, however, the extent of indications attributable to necroptotic cell death is poorly understood. Precisely defining pathologies impacted by necroptosis has posed a challenge owing to the dearth of antibodies validated to specifically detect members of the pathway and their activated (phosphorylated) forms in fixed cells and tissues. As a result, the contribution of necroptosis to many pathologies remains a subject of ongoing debate $22,23,24,25$.

Necroptotic cell death signaling is initiated by ligation of death receptors, such as the TNF receptor 1, or pathogen detectors, such as Toll-like receptors 3 and 4 and the ZBP1/DAI intracellular viral RNA sensor protein. In cellular contexts where the activities of the Inhibitors of Apoptosis proteins (IAPs) E3 Ubiquitin ligase family and the proteolytic apoptotic effector, Caspase-8, are depleted or compromised, necroptosis ensues. The precise choreography of necroptotic signaling is still emerging, although recent studies have defined key events and checkpoints in the pathway ${ }^{26,27,}$ 28, 29. Following pathway induction, RIPK1 autophosphorylation prompts hetero-oligomerization with RIPK3 via an amyloid-forming motif in the region C-terminal to their kinase domains termed the RHIM (RIP Homotypic Interaction Motif) to form a cytoplasmic platform known as the necrosome ${ }^{30,}$ 31, 32. Upon RIPK3 activation by autophosphorylation within necrosomes ${ }^{33}$, 34, RIPK3 is primed to phosphorylate the activation loop of the MLKL pseudokinase domain to activate MLKL's killing function $^{14,20,27,28,35,36,37,38,39}$. In the case of human MLKL, dormant MLKL appears to be at least in 
part pre-associated with RIPK3 in the cytoplasm ${ }^{20,40}$, and stable recruitment to necrosomes appears to be an essential checkpoint in MLKL activation ${ }^{28}$. In the case of mouse MLKL, a transient interaction between RIPK3 and MLKL appears to be sufficient for MLKL activation in mouse cells ${ }^{35}$, 36, 37. Regardless of species, MLKL phosphorylation is thought to provoke a conformational change in the pseudokinase domain that leads to oligomerization and unmasking of the killer N-terminal four-helix bundle (4HB) domain ${ }^{37,40,41,42,43}$. The human MLKL 4HB domain likely engages chaperones to facilitate translocation to the plasma membrane via an actin-, Golgi- and microtubuledependent mechanism, where MLKL accumulates in hotpots. When a threshold is surpassed, the 4HB domains of MLKL permeabilize the membrane to induce cell death ${ }^{26,29}$.

While biochemical studies have defined these steps and checkpoints, visualizing the spatiotemporal dynamics of endogenous proteins during in necroptosis using microscopy-based approaches has proven challenging in the absence of antibodies that have been validated for target specificity. Similarly, the lack of validated reagents poses a challenge to immunohistochemical staining of patient tissue sections, and therefore attribution of a role for necroptosis in pathologies, because knockout tissue controls are not available. Here, we have established procedures for staining endogenous RIPK1, RIPK3 and MLKL, and their phosphorylated forms, in fixed mouse and human cells. While several frequently-used antibodies were found to be suitable for selectively staining these proteins, as validated by comparisons with cells deficient for each protein, many exhibited nonspecific staining and are therefore unsuitable for immunofluorescence and immunohistochemistry. Our studies also highlight the importance of validating antibody compatibility with fixation methods. In most cases, paraformaldehyde fixation ablated epitopes, presumably because RIPK3 and MLKL are lysine-rich and prone to modification by crosslinking, whereas methanol fixation enabled specific detection of these proteins. Due to the sequence divergence between mouse and human RIPK3 and $\operatorname{MLKL}^{41,43,44,45,46}$, it was not possible to specifically-detect proteins across species using a single reagent, which necessitated the development of a new antibody that specifically detected mouse 
MLKL. Collectively, our studies present a toolbox of selective antibodies that will enable critical analysis of the chronology, checkpoints and kinetics of necroptotic signaling in mouse and human cells.

\section{RESULTS}

\section{Immunofluorescent detection of human MLKL}

We recently described a monoclonal antibody, clone 10C2 (source: WEHI Antibody Facility, inhouse), that recognises an epitope centred on residues 413-471 of human MLKL ${ }^{29}$ (Fig. 1a). The initial screen that identified this clone suggested it yielded specific immunosignals when cells were fixed with methanol, but not when cells were fixed with paraformaldehyde. Organic solvents such as methanol preserve cells by precipitating proteins, whereas aldehyde-based agents such as paraformaldehyde fix cells by crosslinking lysines and other primary amines. Because human MLKL is lysine-rich ( $93^{\text {rd }}$ percentile in the cytoplasmic and membrane-associated proteome), paraformaldehyde likely causes widespread crosslinking of MLKL, which in turn masks epitopes and reduces immunoreactivity. As several other necroptotic proteins are lysine-rich, we considered whether the choice of fixative was a critical variable for robust immunodetection of MLKL, RIPK3 and RIPK1 in human and mouse cells. Accordingly, we compared the performance of 22 antibodies for immunofluorescent staining of human HT29 cells and mouse dermal fibroblasts (MDFs) - two cellular models that are well-characterized to undergo necroptosis when treated with TNF, Smacmimetic and IDN-6556 (herein referred to as TSI) $5,28,29,44,47$. To quantitatively gauge the performance of each antibody, their immunosignals were characterized in four ways: 1) A ratio of the immunofluorescent signals between a positive and negative control. This produces a signal-tonoise curve that estimates 'specific signal abundance' (Fig. 1b). For testing phospho-specific antibodies, wild-type cells undergoing necroptosis were used as a positive control and untreated wildtype cells as a negative control (Fig. S1). For testing all other antibodies, untreated wild-type cells 
were used as a positive control and relevant knockout cells as a negative control. 2) Micrographs were gated so that the minimum/maximum immunosignals corresponded to the $5^{\text {th }} / 95^{\text {th }}$ percentiles of the signal-to-noise curve (Fig. 1b). 3) The percentage of total signals that fall within this gate were determined to show how much signal from the positive control was considered specific (Fig. 1c). 4) Antibodies were immunoblotted against positive and negative controls to independently assess their specificity.

Using this approach, we confirmed that clone 10C2 specifically detects endogenous human MLKL in methanol-fixed, but not paraformaldehyde-fixed cells (Fig. 1d-f). The 10C2 clone produces a favourable immunostaining profile, where the specific signals are abundant (Fig. 1e) and these specific signals represent the majority of all detectable signals (Fig.1d). We recently developed another MLKL-specific antibody, clone 7G2 (source: in-house), that recognises an epitope centred on $\alpha \mathrm{F}-\alpha \mathrm{G}$ loop the C-lobe of the human MLKL pseudokinase domain, which differs to the site recognised by the $10 \mathrm{C} 2$ clone $^{29}$. Despite binding a distinct site in human MLKL to $10 \mathrm{C} 2$, the $7 \mathrm{G} 2$ clone shows similar specificity for human MLKL in immunoblot analyses and only yields specific immunofluorescent signals on methanol-fixed cells (Fig. 1d-f). Notably, clone 7G2 is inferior to clone 10C2 for immunofluorescence studies, because specific signals were less abundant (Fig. 1e) and were a minor fraction of all detectable signals (Fig.1d).

We observed that clone EPR9514 (source: Abcam), an antibody raised against phospho-S358 of human MLKL ${ }^{48}$, which is a hallmark of MLKL activation during necroptosis ${ }^{20}$, produced specific and comparable immunofluorescent signals in both methanol- and paraformaldehyde-fixed cells undergoing necroptosis (Fig. 1e). As MLKL can be disulfide-crosslinked during necroptosis ${ }^{49,50}$ (Fig. S2A-B), we tested whether fixation in the presence of $N$-ethylmaleimide (NEM) to prevent further disulfide bonding, or post-fixative treatment with Tris(2-carboxyethyl)phosphine (TCEP) to reduce disulfide bonds, altered the immunofluorescent detection of phospho-MLKL by clone EPR9514. However, neither preventing nor reducing disulfide bonds in fixed cells precluded the 
133

immunodetection of MLKL by clone EPR9514 (Fig. S2C-D). Indeed, disulfide-crosslinking may be a by-product of MLKL activation given that recombinant human MLKL oligomerizes in the absence of disulfide bonds (Fig. S2E).

Two other anti-human MLKL antibodies were found to be non-specific (Novus Biological clone 954702; and Sigma-Aldrich M6697, a polyclonal antibody raised against residues 58-70; Fig. 1a and 1e), with equivalent signal intensity and diffuse staining observed in wild-type and $M L K L^{-/-}$ cells. Lastly, immunoblotting confirmed that clones 10C2, 7G2 (both in-house) and EPR9514 (Abcam) were highly-specific with bands corresponding to human MLKL's molecular weight of $54 \mathrm{kDa}$ observed in wild-type but not $M L K L^{-/}$HT29 cell lysates. In contrast, clone 954702 (Novus Biological MAB9187) and the Sigma-Aldrich M6697 polyclonal antibody were non-specific, with multiple bands not corresponding to the molecular weight of MLKL observed in both wild-type and $M L K L^{-/-}$HT29 cell lysates (Fig. 1g).

In summary, three of the five antibodies that were tested selectively recognised human MLKL in methanol-fixed cells (clones 10C2, 7G2 and EPR9514) and, accordingly, we recommend methanol fixation for detecting endogenous human MLKL by immunofluorescence. Under these conditions, cytoplasmic forms of MLKL could be detected using the 10C2 and 7G2 clones, and phospho-MLKL accumulating at the cell periphery with the EPR9514 clone (Fig. 1f). These data underscore the importance of careful consideration of fixation method when using MLKL as a histological marker of necroptosis.

\section{Immunofluorescent detection of human RIPK3}

We next assessed five anti-human RIPK3 antibodies (Fig. 2a). Two antibodies raised against the Cterminus (source: ProSci 2283, Novus Biological NBP2-24588) and one antibody raised against the N-terminus of RIPK3 (source: Novus Biological MAB7604, clone 780115) yielded non-specific signals via both immunofluorescence and immunoblotting (Fig. 2b-e). Our recently described 
antibody, clone 1H2 (source: in-house) ${ }^{5}$, detected RIPK3 via immunofluorescence in methanol-fixed, but not paraformaldehyde-fixed cells. However, most of the immunofluorescent signals produced by $1 \mathrm{H} 2$ were non-specific (Fig. 2b), and the remaining signals are specific but of very low abundance (Fig. 2c). Thus, although clone $1 \mathrm{H} 2$ is highly-selective when used as an immunoblotting reagent (Fig. $2 d^{5}$ ), it should only be used for the immunofluorescent detection of human RIPK3 under carefully controlled conditions. Our data also showed that clone D6W2T (source: Cell Signaling Technology), an antibody raised against a mark of human RIPK3 activation in necroptosis, phospho-S227, produced specific immunofluorescent signals in paraformaldehyde-fixed cells undergoing necroptosis, but not in methanol-fixed cells (Fig. 2d). Again, the low abundance of these specific immunosignals suggests that clone D6W2T should only be used for immunofluorescence under carefully controlled conditions, such as where $R I P K 3^{-/}$control cells are available for direct comparison. Another caveat is that immunoblotting showed that clone D6W2T not only detected RIPK3 in cells undergoing necroptosis, but also in untreated cells when RIPK3 was presumably not phosphorylated at S227 (Fig. 2d). Therefore, while two of the five antibodies that were tested specifically recognised human RIPK3, the low abundance of their specific signals complicates use of these antibodies for studying endogenous human RIPK3 via immunofluorescence. At present, more specific antibodies are needed to enable the immunofluorescent detection of human RIPK3.

\section{Immunofluorescent detection of human RIPK1}

We next tested three monoclonal anti-RIPK1 antibodies: one against the N-terminal domain (source: Cell Signaling Technology clone D94C12), one against the C-terminal region (source: BD Transduction Laboratories clone 38/RIP) and one raised against phospho-S166 (source: Cell Signaling Technology clone D8I3A; Fig. 3a). All three clones yielded specific immunofluorescent signals in methanol- and paraformaldehyde-fixed cells, however, these signals were more abundant in methanol-fixed samples (Fig. 3b-d). All three clones were also specific via immunoblot (Fig. 3e). 
Importantly, the immunosignals from clones D94C12 and 38/RIP were markedly lower in cells undergoing necroptosis than in unstimulated wild-type cells (Fig. 3d-e). This observation is likely due to RIPK1 undergoing widespread post-translational modification and/or proteasomal degradation during TNF-induced cell death ${ }^{51,52}$. Thus, despite clones D94C12 and 38/RIP exhibiting a favourable immunostaining profile in unstimulated cells, their decreased reactivity in cells undergoing necroptosis indicates that they should be used judiciously for immunofluorescent labelling of samples for accurate analysis of necroptosis. Conversely, while clone D813A preferentially stains RIPK1 in cells undergoing necroptosis, specific signals that were detected also had low intensity (Fig. 3b) and low abundance (Fig. 3c). In summary, three highly-specific antibodies exist for human RIPK1. However, because their specific signals have very low intensity and abundance in necroptotic cells, their use for the immunofluorescent detection of RIPK1 during necroptosis should be carefully controlled, including side-by-side examination of wild-type and $R I P K 1^{-/}$control cells.

\section{Immunofluorescent detection of mouse MLKL}

To our knowledge, there are currently no validated monoclonal antibodies for the immunofluorescent detection for mouse MLKL in unstimulated cells. Accordingly, we raised a monoclonal antibody, clone 5A6 (source: in-house), against full-length mouse MLKL (Fig. 4a). The epitope for clone 5A6 resides in the C-terminal domain of mouse MLKL (Fig. S3). As shown in Fig. 4a-d, clone 5A6 produced specific and abundant signals for endogenous mouse MLKL in methanol-fixed, but not paraformaldehyde-fixed cells. Immunoblotting confirmed that clone 5A6 was highly-specific (Fig. 4e). Notably, compared to human MLKL which translocates en masse into cytoplasmic clusters during necroptosis, the relocation of mouse MLKL into cytoplasmic clusters during necroptosis was more subtle. This observation may relate to the notion that human MLKL is recruited to the necrosome in a more stable manner than mouse MLKL ${ }^{28}$. 
Phosphorylation of mouse MLKL at S345 is essential for necroptosis in murine cells ${ }^{37}$, and

therefore many antibodies have been raised against this phosphosite. We tested three commonly-used

MABC1158) and D6E3G (source: Cell Signaling Technology). All three clones yielded specific

immunosignals in methanol-fixed cells (Fig. 4c), whereas only clone 7C6.1 was compatible with

paraformaldehyde fixation. However, the performance of clone D6E3G was superior to the other antiwith clone 7C6.1 being largely non-specific, clone EPR9515(2) being moderately specific and clone D6E3G exhibiting a high degree of specificity towards activated MLKL in necroptotic cells (Fig. 4e). In summary, clones 5A6 and D6E3G allow the immunofluorescent detection of mouse MLKL under resting and necroptotic conditions, respectively. Moreover, as with human MLKL, methanol is the fixative of choice for robust immunofluorescent detection of endogenous mouse MLKL.

\section{Immunofluorescent detection of mouse RIPK3}

There are numerous well-validated antibodies raised against mouse RIPK3, including a polyclonal antibody against the C-terminus (source: ProSci 2283), and monoclonal antibodies recognising phospho-T231/phospho-S232 (source: Genentech clone GEN135-35-9 ${ }^{53}$ ) and the extended kinase domain (residues 2-353) of mouse RIPK3 (clone 8G755, in-house; Fig. 5a). These antibodies yielded specific signals via both immunofluorescence and immunoblot analyses (Fig. 5b-e). Interestingly, while phospho-RIPK3 concentrates into cytoplasmic clusters during necroptosis, this relocation event was not detected by other, anti-total RIPK3 antibodies (Fig. 5d). This finding suggests that the epitopes for RIPK3 detection are obscured via protein-protein interactions during the chronology of 
and which recognises the translocation of mouse RIPK3 into cytoplasmic clusters during necroptosis

(Fig. 5d). Notably, monoclonal antibodies raised against the N-terminal kinase domain of RIPK3, $8 \mathrm{G} 7$ and 1H12, detected several species of lower molecular weight than full length RIPK3 by immunoblot. These signals are likely to be spliced isoforms of mouse RIPK3 of varying lengths, each of which harbour the kinase domain antigen (residues 2-353), which are therefore not detected by antibodies directed towards the C-terminus of the full-length mouse RIPK3 isoform, such as ProSci 2283. In summary, there are several excellent options for the immunofluorescent detection of endogenous mouse RIPK3. Notably, unlike MLKL and RIPK1, the choice of fixative has no major bearing on the ability to detect mouse RIPK3 by immunofluorescence (Fig. 5c).

\section{Immunofluorescent detection of mouse RIPK1}

RIPK1 exhibits greater sequence identity between mouse and human orthologs than either RIPK3 or $\mathrm{MLKL}^{41}$. In keeping with this, both clone D94C12 (source: Cell Signaling Technology) and clone 38/RIP (source: BD Transduction Laboratories), which were raised against human RIPK1, also specifically detected mouse RIPK1 via immunofluorescence and immunoblotting (Fig. 6a-e). A polyclonal antibody raised against phospho-S166 of mouse RIPK1 (31122; source: Cell Signaling Technology) was also found to specifically detect RIPK1 via immunoblot (Fig. 6e) and in methanolfixed, but not paraformaldehyde-fixed, cells undergoing necroptosis (Fig. 6b-d).

In summary, three highly-specific antibodies exist for mouse RIPK1. However, as was observed in human cells, necroptosis in mouse cells causes a marked reduction in RIPK1 levels (Fig. $6 \mathrm{~d}-\mathrm{e})$. Thus, the specific immunosignals from the antibodies tested are of low intensity and abundance in necroptotic cells. Therefore, careful gating of signals is recommended for the study of mouse RIPK1 in necroptotic cells. 
Having validated and compared the performance of numerous reagents, we now propose different

antibody combinations that can be used to study endogenous necroptotic signaling (Fig. 7a-b).

Because these recommendations are made to facilitate the investigation of endogenous necroptotic

signaling in fixed cells, we also provide an ImageJ macro to generate signal-to-noise curves for the gating of specific immunosignals (Supplementary File 1). To exemplify the advantages of visualising endogenous necroptotic events in situ, we co-stained MDFs for non-phosphorylated MLKL (clone concentrate into cytoplasmic clusters during necroptosis. However, this compartmentalisation event is less pronounced than those observed for human MLKL in necroptotic HT29 cells (arrowhead; Fig. 7c). Also similar to what was described for human MLKL $^{29}$, phosphorylated MLKL was observed to form focal structures at the plasma membrane, rather than docking uniformly with the cell periphery (Fig. 7c). Remarkably, although smaller than the hotspots of phosphorylated human MLKL that form in necroptotic HT29 cells, junctional accumulations of phosphorylated mouse MLKL were also 271 apparent in necroptotic MDFs (Fig. 7d and Supplementary Video 1). These data suggest that the assembly of both mouse and human MLKL into macromolecular structures at the plasma membrane, and preferentially at sites of intercellular contact, may be an intrinsic and penultimate feature of necroptotic signaling.

\section{DISCUSSION}

277 Here, we profiled the immunofluorescent staining of MLKL, RIPK3 and RIPK1 in fixed human and 278 mouse cells with a panel of 22 antibodies. While 17 of 22 antibodies were capable of detecting their 279 respective necroptotic protein target in fixed wild-type cells and not their knockout counterparts, only 28014 of 22 antibodies exhibited favourable signal-to-noise for robust immunostaining (as summarized 281 in Fig. 7a). 
The choice of fixative was a critical variable for the immunofluorescent detection of necroptotic proteins. With the exception of phospho-S227 in human RIPK3 and pT231/pS232 in mouse RIPK3, all other epitopes exhibited increased immunoreactivity in methanol-fixed samples. Indeed, immunodetection of MLKL was often found to be entirely contingent upon the use of methanol as a fixative. This observation has ramifications for the experimental and clinical immunohistological detection of cell death, which is almost exclusively performed on aldehyde-fixed samples. Thus, stringent antigen retrieval steps to reverse crosslinks will likely be necessary for the development of a diagnostic assay for necroptosis in patient samples. High resolution microscopy is also mostly performed on aldehyde-fixed cell monolayers. However, as these cell monolayers cannot typically withstand antigen retrieval, we recommend the use of methanol fixation for high resolution immunofluorescence of necroptosis; even though methanol fixation can be sub-optimal for both the retention of certain biomolecules ${ }^{54}$ and the preservation of cellular architecture ${ }^{55,56}$. Indeed, all but one of the antibodies (source: Cell Signaling Technology clone D6W2T) in the suggested toolbox in Fig. 7a are compatible with methanol fixation.

Our data underscore the importance of using controlled experimental conditions to maximise the identification of specific immunosignals. To this end, we used wild-type cells that express high levels of MLKL, RIPK3 and RIPK1, and which have a well-characterised response to necroptotic stimuli. If possible, cell cultures should be fixed when low, but measurable, levels of necroptotic death are occurring (Fig. S1). This is because end-stage dead cells are often lost during/after methanol 301 fixation, and because the immunosignals for phospho-RIPK1, phospho-RIPK3 and phospho-MLKL peak prior to cell death ${ }^{29}$. Notably, the use of knockout cells (for non-phospho-targets) or unstimulated wild-type cells (for phospho-sites) as a negative control is critical, as it provides the information needed to define the signal-to-noise profile of an antibody (Fig. 1b). Additionally, it is also helpful if different antibodies directed toward the same target yield concordant immunofluorescent signals, and if accompanying immunoblot data confirm their specificity. This 
combined approach was important for deducing that clone D6E3G (source: Cell Signaling Technology) is the best option for detecting phospho-MLKL in mouse cells (Fig. 4). while numerous studies use the ProSci 2283 antibody to detect human RIPK3 ${ }^{57,58,59}$, we found that it only recognised mouse RIPK3. Similarly, M6697 (source: Sigma-Aldrich) and clone 7C6.1 (source: Millipore) have been widely used to respectively detect human MLKL and mouse MLKL phospho-S345 ${ }^{39,60,61,62,63,64,65}$, however these reagents exhibited a low degree of specificity in our hands. Nonetheless, as we did not exhaustively test the performance of these antibodies for immunofluorescence using a wide variety of fixatives, blocking agents, and detergents, we cannot categorically state that they are non-selective. Moreover, as ProSci 2283 (reported to detect mouse and human RIPK3) and Sigma-Aldrich M6697 (reported to detect human MLKL) are polyclonal antibodies, batch-to-batch variation may explain differences in their specificity between studies. It is also noteworthy that the majority of monoclonal antibodies that yielded the most abundant and specific signals were raised against recombinant full-length protein or component domains, rather than unfolded partial domains or peptides. We reasoned that epitopes that are exposed in the cellular forms of these proteins would be similarly presented within a folded protein for immune recognition in the host. Phosphosite-specific antibodies differ in this regard; these were raised using linear phosphopeptides and their specificity likely reflects the unstructured and solvent-exposed nature of the sequences in which they reside.

Broadly, the specific immunosignals described in this study provide consensus about three 327 key compartmentalisation events that underlie necroptotic signaling ${ }^{66}$. First, the core necroptotic proteins - MLKL, RIPK3 and RIPK1 - predominantly reside in the cytosol under basal conditions. exists as small puncta that are below the resolution limit of conventional light microscopy. It may be that these necroptotic proteins are preassembled into a membrane-less organelle under basal 
conditions. Second, RIPK1, RIPK3 and MLKL then coalesce into large cytoplasmic clusters. These clusters preferentially locate to the perinuclear space and are necrosome-related as they co-stain for the presence of phospho-RIPK1, -RIPK3 and -MLKL (Fig. 1-7 and ref. ${ }^{29}$ ). It is important to note that the formation of these necrosomal clusters in TSI-treated HT29 cells occurs subsequent to the phosphorylation of $\mathrm{MLKL}^{29}$. While these clusters likely represent a higher-order form of the necrosome, the mechanisms that govern cluster formation and limit their overall size are currently unknown. Third, as necroptotic signaling continues, phospho-MLKL is actively trafficked away from the clusters towards the plasma membrane ${ }^{26}$ where it accumulates into supramolecular assemblies called "hotspots" 29 . Recent findings suggest the release of phospho-MLKL from clusters arises from MLKL undergoing a conformational change that accompanies disengagement from necrosomal RIPK $3{ }^{40}$. Our data support such a disengagement step because neither RIPK1 nor RIPK3 were observed to accumulate at the plasma membrane during necroptosis in mouse or human cells (Fig. 23 and 5-6). This disengagement step, and formation of supramolecular assemblies by both mouse and human MLKL at the plasma membrane, are likely to be two additional checkpoints in necroptotic signaling.

\section{METHODS}

Materials - Primary antibodies and the dilutions used for immunoblotting/immunofluorescence were: rat anti-human MLKL (clone 10C2; produced in-house ${ }^{29} ; 1: 2000 / 1: 400$ ), rat anti-human MLKL (clone 7G2; produced in-house ${ }^{29} ; 1: 2000 / 1: 400$ ), rabbit anti-phospho-S358 human MLKL (Abcam ab187091; clone EPR9514; 1:2000/1:200), rat anti-mouse, human, rat, horse MLKL (clone 3H1; produced in-house ${ }^{37}$ and available as Millipore MABC604; 1:2000/ N/A), mouse anti-phosphoT357 human MLKL (Novus Biological MAB9187; clone 954702; 1:1000/1:200), rabbit anti-human MLKL (Sigma-Aldrich M6697; 1:1000/1:200), rabbit anti-RIPK3 (ProSci \#2283; 1:1000/1:200), rabbit anti-human RIPK3 (Novus Biological NBP2-24588; 1:1000/1:200), mouse anti-human RIPK3 
(Novus Biological; clone 780115; 1:1000/1:200), rat anti-human RIPK3 (clone 1H2; produced inhouse $^{5}$ and available as Millipore MABC1640; 1:2000/1:400), rabbit anti-phospho-S227 human RIPK3 (Cell Signaling Technology; clone D6W2T; 1:2000/1:200), rabbit anti-mouse or human RIPK1 (Cell Signaling Technology; clone D94C12; 1:2000/1:200), mouse anti-mouse or human RIPK1 (BD Biosciences; clone 38/RIP; 1:1000/1:100), rabbit anti-phospho-S166 human RIPK1 (Cell Signaling Technology; clone D8I3A; 1:2000/1:200), rat anti-mouse MLKL (clone 5A6; produced inhouse), rabbit anti-phospho-S345 mouse MLKL (Abcam; clone EPR9515(2); 1:2000/1:200), mouse anti-phospho-S345 mouse MLKL (Millipore MABC158; clone 7C6.1; 1:2000/1:200), rabbit antiphospho-S345 mouse MLKL (Cell Signaling Technology; clone D6E3G; 1:2000/1:200), rat antimouse RIPK3 (clone 8G7; produced in-house ${ }^{5}$ and available from Millipore as MABC1595; 1:2000/1:400), rat anti-mouse RIPK3 (clone 1H12; produced in-house; 1:2000/1:400), rabbit antiphospho-T231/S232 mouse RIPK3 (Genentech; clone GEN135-35-953; 1:2000/1:400), rabbit antiphospho-S166 mouse RIPK1 (Cell Signaling Technology 31122; 1:2000/1:200), mouse anti-GAPDH (Millipore MAB374; 1:2000/N/A). Secondary antibodies for immunoblotting were: horseradish peroxidase (HRP)-conjugated goat anti-rat IgG (Southern Biotech 3010-05), HRP-conjugated goat anti-mouse IgG (Southern Biotech 1010-05), and HRP-conjugated goat anti-rabbit IgG (Southern Biotech 4010-05). All secondary antibodies for immunoblotting were used at a dilution of 1:10000. Secondary immunofluorescence detection reagents were: AlexaFluor647-conjugated donkey antirabbit IgG (ThermoFisher Scientific A31573), AlexaFluor568-conjugated donkey anti-rabbit IgG (ThermoFisher Scientific A10042), AlexaFluor568-conjugated donkey anti-mouse IgG (ThermoFisher Scientific A10037), AlexaFluor-594 donkey anti-rat IgG (ThermoFisher Scientific A21209), AlexaFluor488-conjugated donkey anti-rat IgG (ThermoFisher Scientific A21208). All secondary antibodies for immunofluorescence were used at a dilution of 1:1000. Bond-Breaker TCEP solution (ThermoFisher Scientific 77720). N-Ethylmaleimide (Sigma-Aldrich E3876). 
5 A6 and 1 H12 antibody production - Antibodies were generated at the Walter and Eliza Hall

Institute Monoclonal Antibody Facility by immunizing Wistar rats with recombinant full-length mouse $\mathrm{MLKL}^{37}$ for clone 5A6 or recombinant mouse RIPK3 residues 2-353 for clone $1 \mathrm{H} 12$ and the previously-reported clone $8 \mathrm{G} 7^{5}$ that was expressed and purified from Sf21 insect cells using the baculovirus expression system, before splenocytes were fused with SP2/O mouse myeloid cells and arising hybridoma lines cloned. The specificity of clone 5A6 for mouse MLKL was validated via immunoblot analyses as exemplified in Fig. 4e and Fig. S3. The specificity of clone 1H12 for mouse RIPK3 was validated via immunoblot analyses as exemplified in Fig. 5e.

Cell lines - HT29 cells were provided by Mark Hampton (University of Otago). RIPK1 $1^{-/}, R_{I P K 3^{-/-}}$ and $M L K L^{-/-}$HT29 cells have been previously reported ${ }^{28,29,67}$. MDF lines were generated in-house from the tails of wild-type C57BL/6J, Mlkl ${ }^{-/ 37}$ and Ripk3 $^{-/-68}$ mice and immortalized by SV40 large T antigen as reported previously ${ }^{35,37}$. The sex and precise age of these animals were not recorded, although our MDFs are routinely derived from tails from 8-week-old mice. $M l k l^{-/}$Ripk $1^{-/-}$MDFs were derived from the belly/back dermis of $\mathrm{Mlkl}^{-/}$Ripk1 ${ }^{-/}$E19.5 mice ${ }^{16}$ and immortalized as described above. MDF lines were generated in accordance with protocols approved by the Walter and Eliza Hall Institute of Medical Research Animal Ethics Committee. Cell line identities were not further validated, although their morphologies and responses to necroptotic stimuli were consistent with their stated origins. Cell lines were routinely monitored to confirm they were mycoplasma-free.

Cell culture - HT29 cells were maintained in Dulbecco's Modified Eagle Medium (DMEM; Life Technologies) containing $8 \% \mathrm{v} / \mathrm{v}$ heat-inactivated fetal calf serum (FCS), $2 \mathrm{mM}$ L-Glutamine/404 GlutaMAX (ThermoFisher Scientific 35050061), $50 \mathrm{U} \mathrm{ml}^{-1}$ penicillin and $50 \mathrm{U} \mathrm{ml}^{-1}$ streptomycin 405 (G/P/S) under humidified $10 \% \mathrm{CO}_{2}$ at $37^{\circ} \mathrm{C}$. 
Cell Treatment - Cells were seeded into Ibi-treated 8-well $\mu$-slides (Ibidi 80826) in media containing

$8 \% \mathrm{v} / \mathrm{v}$ FCS and G/P/S at $3.0 \times 10^{4}$ cells per well for HT29 and $0.25 \times 10^{4}$ cells per well for MDFs.

Cells were left to adhere overnight then treated in media containing $1 \% \mathrm{v} / \mathrm{v}$ FCS and G/P/S and

supplemented with the following stimuli: $100 \mathrm{ng} / \mathrm{mL}$ recombinant human TNF- $\alpha-\mathrm{Fc}$ (produced in-

house as in ref. ${ }^{69}$ ), 500nM Smac mimetic/Compound A (provided by Tetralogic Pharmaceuticals; as

in ref. $^{70}$ ), $5 \mu \mathrm{M}$ IDN-6556 (provided by Tetralogic Pharmaceuticals). Unless stipulated, HT29 cells were stimulated for $7.5 \mathrm{~h}$ with TSI and MDF cells were stimulated for $90 \mathrm{~min}$ with TSI.

LDH release - Colorimetric LDH release assay kit (Promega G1780) was performed according to manufacturer's instructions.

Whole cell lysate, SDS-PAGE, immunoblot \& quantification - Cells were lysed in ice-cold RIPA buffer (10mM Tris-HCl pH 8.0, 1mM EGTA, $2 \mathrm{mM} \mathrm{MgCl}_{2}, 0.5 \%$ v/v Triton X100, 0.1\% w/v Na deoxycholate, $0.5 \% \mathrm{w} / \mathrm{v}$ SDS and $90 \mathrm{mM} \mathrm{NaCl}$ ) supplemented with 1x Protease \& Phosphatase Inhibitor Cocktail (Cell Signaling Technology 5872S) and 100U/mL Benzonase (Sigma-Aldrich E1014). Whole cell lysates were boiled for 10 minutes in $1 \times$ SDS Laemmli sample buffer (126 mM

423 Tris-HCl, $\mathrm{pH} 8,20 \% \mathrm{v} / \mathrm{v}$ glycerol, 4\% w/v SDS, $0.02 \% \mathrm{w} / \mathrm{v}$ bromophenol blue, 5\% v/v 2424 mercaptoethanol), and resolved on 1.5mm NuPAGE 4-12\% Bis-Tris gels (ThermoFisher Scientific NP0335BOX) using MES Running buffer (ThermoFisher Scientific NP000202) or Bio-Rad Criterion TGX 4-15\% gels (Bio-Rad 5678085) using 1x TGS buffer (Bio-Rad 1610772). After transfer onto 427 nitrocellulose, membranes were blocked in 5\% w/v skim milk powder in TBS-T, probed with primary 428 antibodies (see Materials above) then the appropriate HRP-conjugated secondary antibody (see 429 Materials above) and signals revealed by enhanced chemiluminescence (Merck P90720) on a 430 ChemiDoc Touch Imaging System (Bio-Rad). Between each probe, membranes were incubated in 
stripping buffer $(200 \mathrm{mM}$ glycine $\mathrm{pH} 2.9,1 \% \mathrm{w} / \mathrm{v}$ SDS, $0.5 \mathrm{mM}$ TCEP) for 30 minutes at room temperature then re-blocked.

Subcellular fractionation, BN-PAGE \& immunoblot-HT29 cells or MDFs were seeded into 6-well plates $\left(1.0 \times 10^{6}\right.$ cells per well $)$ in media containing $8 \% \mathrm{v} / \mathrm{v} \mathrm{FCS}$ and $\mathrm{G} / \mathrm{P} / \mathrm{S}$ and equilibrated overnight under humidified $10 \% \mathrm{CO}_{2}$ at $37{ }^{\circ} \mathrm{C}$ conditions. Cells were then treated in media containing $1 \%$ FCS and $\mathrm{G} / \mathrm{P} / \mathrm{S}$ supplemented with the agonists (as indicated above). Cells were fractionated into cytoplasmic and membrane fractions ${ }^{35}$. Cells were permeabilized in MELB buffer (20 mM HEPES $\mathrm{pH} 7.5,100 \mathrm{mM} \mathrm{KCl}, 2.5 \mathrm{mM} \mathrm{MgCl} 2$ and $100 \mathrm{mM}$ sucrose, $0.025 \% \mathrm{v} / \mathrm{v}$ digitonin, $2 \mu \mathrm{M}$ N-ethyl maleimide, phosphatase and protease inhibitors). Crude membrane and cytoplasmic fractions were separated by centrifugation ( 5 minutes $11,000 \mathrm{~g}$ ), and fractions prepared in buffers to a final concentration of $1 \% \mathrm{w} / \mathrm{v}$ digitonin. The samples were resolved on a $4-16 \%$ Bis-Tris Native PAGE gel (ThermoFisher), transferred to polyvinylidene difluoride (Merck IPVH00010). After transfer, membranes were destained (in 50\% (v/v) methanol, 25\% (v/v) acetic acid), denatured (in $6 \mathrm{M}$ Guanidine hydrochloride, $10 \mathrm{mM}$ Tris pH6.8, $5 \mathrm{mM} \beta$-mercaptoethanol), blocked in 5\% skim milk (Diploma), and probed in the same manner as above.

Protein production and purification - Full-length human and mouse MLKL and the C-terminal, pseudokinase domain of mouse and human MLKL were expressed in Sf21 insect cells using the Bacto-Bac system (ThermoFisher Scientific) and purified using established procedures ${ }^{28,37,42}$. Briefly, proteins were expressed with an N-terminal, TEV protease-cleavable GST (full length human MLKL) or His 6 (full length mouse MLKL and pseudokinase domains) tags and captured from lysates using glutathione resin (UBP Bio) or HisTag Ni-NTA resin (Roche) respectively. Proteins were cleaved on-resin from the GST tag or off-resin for His 6 tags using His-tagged TEV protease, before protease was removed by Ni-NTA chromatography (HisTag resin, Roche). Protein was concentrated by 
centrifugal ultrafiltration and applied to a Superdex-200 (GE Healthcare) size exclusion

457 chromatography column; protein was eluted in $20 \mathrm{mM}$ HEPES $\mathrm{pH} \mathrm{7.5,} 200 \mathrm{mM} \mathrm{NaCl}, 5 \% \mathrm{v} / \mathrm{v}$ glycerol. Protein containing fractions were spin concentrated to $5-10 \mathrm{mg} / \mathrm{mL}$, aliquoted, snap frozen in liquid $\mathrm{N}_{2}$ and stored at $-80^{\circ} \mathrm{C}$ until required.

Immunofluorescence - Cells in 8-well $\mu$-Slides (Ibidi 80826) were ice-chilled for 3 minutes, then washed in ice-cold Dulbecco's PBS (dPBS; ThermoFisher Scientific 14190144), then fixed for 30 minutes in either ice-cold methanol or ice-cold 4\% w/v PFA. Cells were washed twice in ice-cold dPBS, then blocked in ice-cold Tris-balanced salt solution with $0.05 \% \mathrm{v} / \mathrm{v}$ Triton-X100 (TBS-T) supplemented with 10\% v/v donkey serum (Sigma-Aldrich D9663) for $>1$ hour. Cells were incubated in primary antibodies (see Materials above) overnight at $4{ }^{\circ} \mathrm{C}$ in TBS-T with $10 \% \mathrm{v} / \mathrm{v}$ donkey serum.

Cells were washed twice in TBS-T then incubated in the appropriate secondary antibodies supplemented with $0.1 \mu \mathrm{g} / \mathrm{mL}$ Hoechst 33342 (ThermoFisher Scientific H3570) for 3 hours at room temperature with gentle rocking. Cells were washed four times in ice-cold TBS-T then stored at $4{ }^{\circ} \mathrm{C}$ until imaged. Where indicated, to demarcate the plasma membrane, $2 \mu \mathrm{L}$ of biotinylated wheat germ agglutinin (Sigma-Aldrich L5142) was added to each well 10 minutes before fixation. The fixed wheat germ agglutinin was then detected via the addition of 1:1000 dilution of DyLight650conjugated streptavidin (ThermoFisher Scientific 84547) during the secondary antibody incubation step.

Two-dimensional epifluorescence microscopy - Samples in TBS-T were imaged on an Inverted Axio Observer.Z1 microscope (Zeiss) with the following specifications: C-Apochromat 40x/1.20 W autocorr UV VIS IR lens, HXP 120V excitation source, AlexaFluor647 and DyLight650 imaged with a $\lambda_{\text {Excitation }}=625-655 \mathrm{~nm} ; \lambda_{\text {beamsplitter }}=660 \mathrm{~nm} ; \lambda_{\text {Emission }}=665-715 \mathrm{~nm}$ filter, AlexaFluor568 imaged with a 
$\lambda_{\text {Excitation }}=450-490 \mathrm{~nm} ; \lambda_{\text {beamsplitter }}=495 \mathrm{~nm} ; \lambda_{\text {Emission }}=500-550 \mathrm{~nm}$, Hoechst 33342 imaged with a

$\lambda_{\text {Excitation }}=359-371 \mathrm{~nm} ; \lambda_{\text {beamsplitter }}=395 \mathrm{~nm} ; \lambda_{\text {Emission }}=397-\infty \mathrm{nm}$, a sCMOS PCO.edge 4.2 camera, ZEN

blue 2.5 pro capture software and ImageJ $1.53 \mathrm{c}$ post-acquisition processing software ${ }^{71}$. Typically, for

each independent experiment, 5-10 randomly selected fields were captured per treatment group,

whereby only the Hoechst 33342 signal was visualised prior to multi-channel acquisition. To ensure

consistent signal intensities across independent experiments, the same excitation, emission and camera settings were used throughout this study.

Airyscan microscopy - Fixed immunostained cells in 8-well $\mu$-Slides (Ibidi 80827) were subjected

to super-resolution 3-dimensional Airyscan microscopy on an Inverted LSM 880 platform (Zeiss)

equipped with the following specifications: a 63x/1.4 N.A. PlanApo DIC M27 oil immersion objective (Zeiss), 405-, 488-, 568- and 640-nm laser lines, and radially-stacked Airyscan GaASP deconvolution was performed using the automated '3D AiryScan Processing' function of ZEN blue software.

Hotspot quantitation - Micrographs (captured as in two-dimensional epifluorescence microscopy) immunosignals thresholded ( $\geq 7000$ units) and objects segmented using the 'Analyze $>$ Analyze

501 Particles' tool. Segmented objects with size $0.5-100 \mu \mathrm{m}^{2}$ and feret diameter $>2$ (i.e. elliptical objects) hotspot occurrence. The mean size of the segmented objects was taken as an index of hotspot size.

504 The fluorescence intensity of each segmented object divided by its size was taken as an index of hotspot intensity. 


\section{ACKNOWLEDGEMENTS}

508 We thank the Walter and Eliza Hall Institute Monoclonal Antibody Facility for their assistance 509 generating clones 3H1, 10C2, 7G2, 1H2, 5A6, 8G7 and 1H12; and Cathrine Hall for assistance generating $\mathrm{Mlkl}^{-/-}$Ripkl $^{-/-}$MDF lines. We are grateful to the Australian National Health and Medical 511 Research Council for fellowship (J.M.H., 1142669; E.D.H., 1159488; J.M.M., 1172929), grant 512 (1124735, 1124737, and 1105023), and infrastructure (IRIISS 9000587) support, with additional 513 support from the CASS Foundation (A.L.S.) and the Victorian Government Operational 514 Infrastructure Support scheme. We acknowledge the support for A.V.J. from an Australian Research 515 Training Program Scholarship.

\section{AUTHOR CONTRIBUTIONS}

Investigation: A.L.S., K.P., C.F., J.M.H., L.W., J.R., A.V.J., C.R.H., X.G., S.N.Y. Supervision and Methodology: A.L.S., J.M.H., K.L.R., E.D.H. and J.M.M.; Conceptualization: A.L.S., E.D.H. and J.M.M.; Writing - Original Draft: A.L.S. and J.M.M.; Writing - Review \& Editing: all authors.

\section{COMPETING INTERESTS}

A.L.S., K.P. C.F., J.M.H., S.N.Y. and J.M.M. contribute to a project developing necroptosis inhibitors in collaboration with Anaxis Pharma. The other authors declare no competing interests.

\section{MATERIALS REQUESTS}

All materials will be provided under Materials Transfer Agreement upon request to James Murphy (jamesm@wehi.edu.au).

\section{REFERENCES}


1. Cho YS, Challa S, Moquin D, Genga R, Ray TD, Guildford M, et al. Phosphorylation-driven assembly of the RIP1-RIP3 complex regulates programmed necrosis and virus-induced inflammation. Cell 2009, 137(6): 1112-1123.

2. Guo H, Omoto S, Harris PA, Finger JN, Bertin J, Gough PJ, et al. Herpes simplex virus suppresses necroptosis in human cells. Cell Host Microbe 2015, 17(2): 243-251.

3. Pearson JS, Giogha C, Muhlen S, Nachbur U, Pham CL, Zhang Y, et al. EspL is a bacterial cysteine protease effector that cleaves RHIM proteins to block necroptosis and inflammation. Nat Microbiol 2017, 2: 16258.

4. Pearson JS, Murphy JM. Down the rabbit hole: Is necroptosis truly an innate response to infection? Cell Microbiol 2017, 19(8): e12750.

5. Petrie EJ, Sandow JJ, Lehmann WIL, Liang LY, Coursier D, Young SN, et al. Viral MLKL 2019, 28(13): 3309-3319 e3305.

6. Fletcher-Etherington A, Nobre L, Nightingale K, Antrobus R, Nichols J, Davison AJ, et al.

7. Kitur K, Wachtel S, Brown A, Wickersham M, Paulino F, Penaloza HF, et al. Necroptosis Cell reports 2016, 16(8): 2219-2230.

9. Simpson J, Loh Z, Ullah MA, Lynch JP, Werder RB, Collinson N, et al. Respiratory Syncytial 
10. Muller T, Dewitz C, Schmitz J, Schroder AS, Brasen JH, Stockwell BR, et al. Necroptosis and ferroptosis are alternative cell death pathways that operate in acute kidney failure. Cell Mol Life Sci 2017, 74(19): 3631-3645.

11. Pefanis A, Ierino FL, Murphy JM, Cowan PJ. Regulated necrosis in kidney ischemiareperfusion injury. Kidney Int 2019, 96(2): 291-301.

12. Luedde M, Lutz M, Carter N, Sosna J, Jacoby C, Vucur M, et al. RIP3, a kinase promoting necroptotic cell death, mediates adverse remodelling after myocardial infarction. Cardiovasc Res 2014, 103(2): 206-216.

13. Hildebrand JM, Kauppi M, Majewski IJ, Liu Z, Cox AJ, Miyake S, et al. A missense mutation in the MLKL brace region promotes lethal neonatal inflammation and hematopoietic dysfunction. Nat Commun 2020, 11(1): 3150.

14. Wang H, Sun L, Su L, Rizo J, Liu L, Wang LF, et al. Mixed Lineage Kinase Domain-like Protein MLKL Causes Necrotic Membrane Disruption upon Phosphorylation by RIP3. Mol Cell 2014, 54(1): 133-146.

15. Rickard JA, Anderton H, Etemadi N, Nachbur U, Darding M, Peltzer N, et al. TNFR1dependent cell death drives inflammation in Sharpin-deficient mice. Elife 2014, 3: e03464.

16. Rickard JA, O'Donnell JA, Evans JM, Lalaoui N, Poh AR, Rogers TW, et al. RIPK1 regulates RIPK3-MLKL driven systemic inflammation and emergency hematopoiesis. Cell 2014, 157(2): 1175-1188.

17. Pierdomenico M, Negroni A, Stronati L, Vitali R, Prete E, Bertin J, et al. Necroptosis is active in children with inflammatory bowel disease and contributes to heighten intestinal inflammation. Am J Gastroenterol 2014, 109(2): 279-287.

18. He S, Wang L, Miao L, Wang T, Du F, Zhao L, et al. Receptor interacting protein kinase-3 determines cellular necrotic response to TNF-alpha. Cell 2009, 137(6): 1100-1111. 
19. Zhang DW, Shao J, Lin J, Zhang N, Lu BJ, Lin SC, et al. RIP3, an energy metabolism regulator that switches TNF-induced cell death from apoptosis to necrosis. Science 2009, 325(5938): 332-336.

20. Sun L, Wang H, Wang Z, He S, Chen S, Liao D, et al. Mixed lineage kinase domain-like protein mediates necrosis signaling downstream of RIP3 kinase. Cell 2012, 148(1-2): 213227.

21. Zhao J, Jitkaew S, Cai Z, Choksi S, Li Q, Luo J, et al. Mixed lineage kinase domain-like is a key receptor interacting protein 3 downstream component of TNF-induced necrosis. Proc Natl Acad Sci U S A 2012, 109(14): 5322-5327.

22. Wang $\mathrm{T}$, Perera ND, Chiam MDF, Cuic B, Wanniarachchillage N, Tomas D, et al. Necroptosis is dispensable for motor neuron degeneration in a mouse model of ALS. Cell Death Differ 2019.

23. Dermentzaki G, Politi KA, Lu L, Mishra V, Perez-Torres EJ, Sosunov AA, et al. Deletion of Ripk3 Prevents Motor Neuron Death In Vitro but not In Vivo. eNeuro 2019, 6(1).

24. Dominguez S, Varfolomeev E, Brendza R, Stark K, Tea J, Imperio J, et al. Genetic inactivation of RIP1 kinase does not ameliorate disease in a mouse model of ALS. Cell Death Differ 2020.

25. Dara L, Johnson H, Suda J, Win S, Gaarde W, Han D, et al. Receptor interacting protein kinase 1 mediates murine acetaminophen toxicity independent of the necrosome and not through necroptosis. Hepatology 2015, 62(6): 1847-1857.

26. Petrie EJ, Birkinshaw RW, Koide A, Denbaum E, Hildebrand JM, Garnish SE, et al. Identification of MLKL membrane translocation as a checkpoint in necroptotic cell death using Monobodies. Proc Natl Acad Sci U S A 2020, 117(15): 8468-8475.

27. Petrie EJ, Czabotar PE, Murphy JM. The Structural Basis of Necroptotic Cell Death Signaling. Trends Biochem Sci 2019, 44(1): 53-63. 
28. Petrie EJ, Sandow JJ, Jacobsen AV, Smith BJ, Griffin MDW, Lucet IS, et al. Conformational switching of the pseudokinase domain promotes human MLKL tetramerization and cell death by necroptosis. Nat Commun 2018, 9(1): 2422.

29. Samson AL, Zhang Y, Geoghegan ND, Gavin XJ, Davies KA, Mlodzianoski MJ, et al. MLKL trafficking and accumulation at the plasma membrane control the kinetics and threshold for necroptosis. Nat Commun 2020, 11(1): 3151.

30. Li J, McQuade T, Siemer AB, Napetschnig J, Moriwaki K, Hsiao YS, et al. The RIP1/RIP3 necrosome forms a functional amyloid signaling complex required for programmed necrosis. Cell 2012, 150(2): 339-350.

31. Mompean M, Li W, Li J, Laage S, Siemer AB, Bozkurt G, et al. The Structure of the Necrosome RIPK1-RIPK3 Core, a Human Hetero-Amyloid Signaling Complex. Cell 2018, 173(5): 1244-1253 e1210.

32. Sun X, Yin J, Starovasnik MA, Fairbrother WJ, Dixit VM. Identification of a novel homotypic interaction motif required for the phosphorylation of receptor-interacting protein (RIP) by RIP3. J Biol Chem 2002, 277(11): 9505-9511.

33. Cook WD, Moujalled DM, Ralph TJ, Lock P, Young SN, Murphy JM, et al. RIPK1- and RIPK3-induced cell death mode is determined by target availability. Cell Death Differ 2014, 21(10): 1600-1612.

34. Orozco S, Yatim N, Werner MR, Tran H, Gunja SY, Tait SW, et al. RIPK1 both positively and negatively regulates RIPK3 oligomerization and necroptosis. Cell Death Differ 2014, 21(10): 1511-1521.

35. Hildebrand JM, Tanzer MC, Lucet IS, Young SN, Spall SK, Sharma P, et al. Activation of the pseudokinase MLKL unleashes the four-helix bundle domain to induce membrane localization and necroptotic cell death. Proc Natl Acad Sci U S A 2014, 111(42): 1507215077. 
36. Murphy JM. The Killer Pseudokinase Mixed Lineage Kinase Domain-Like Protein (MLKL). Cold Spring Harb Perspect Biol 2020, 12(8).

37. Murphy JM, Czabotar PE, Hildebrand JM, Lucet IS, Zhang JG, Alvarez-Diaz S, et al. The pseudokinase MLKL mediates necroptosis via a molecular switch mechanism. Immunity 2013, 39(3): 443-453.

38. Tanzer MC, Tripaydonis A, Webb AI, Young SN, Varghese LN, Hall C, et al. Necroptosis signalling is tuned by phosphorylation of MLKL residues outside the pseudokinase domain activation loop. The Biochemical journal 2015, 471(2): 255-265.

39. Rodriguez DA, Weinlich R, Brown S, Guy C, Fitzgerald P, Dillon CP, et al. Characterization of RIPK3-mediated phosphorylation of the activation loop of MLKL during necroptosis. Cell Death Differ 2016, 23(1): 76-88.

40. Garnish SE, Meng Y, Koide A, Sandow JJ, Denbaum E, Jacobsen AV, et al. Conformational interconversion of MLKL and disengagement from RIPK3 precedes cell death by necroptosis. Under review.

41. Davies KA, Fitzgibbon C, Young SN, Garnish SE, Yeung W, Coursier D, et al. Distinct pseudokinase domain conformations underlie divergent activation mechanisms among vertebrate MLKL orthologues. Nat Commun 2020, 11(1): 3060.

42. Murphy JM, Lucet IS, Hildebrand JM, Tanzer MC, Young SN, Sharma P, et al. Insights into the evolution of divergent nucleotide-binding mechanisms among pseudokinases revealed by crystal structures of human and mouse MLKL. The Biochemical journal 2014, 457(3): 369377.

43. Tanzer MC, Matti I, Hildebrand JM, Young SN, Wardak A, Tripaydonis A, et al. Evolutionary divergence of the necroptosis effector MLKL. Cell Death Differ 2016, 23(7): 1185-1197. 
44. Davies KA, Tanzer MC, Griffin MDW, Mok YF, Young SN, Qin R, et al. The brace helices of MLKL mediate interdomain communication and oligomerisation to regulate cell death by necroptosis. Cell Death Differ 2018, 25(9): 1567-1580.

45. Dondelinger Y, Hulpiau P, Saeys Y, Bertrand MJM, Vandenabeele P. An evolutionary perspective on the necroptotic pathway. Trends Cell Biol 2016, 26(10): 721-732.

46. Newton K, Manning G. Necroptosis and Inflammation. Annu Rev Biochem 2016, 85: 743763.

47. Petrie EJ, Birkinshaw RW, Koide A, Denbaum E, Hildebrand JM, Garnish SE, et al. Identification of MLKL membrane translocation as a checkpoint in necroptotic cell death using Monobodies. Proc Natl Acad Sci U S A 2020.

48. Wang H, Sun L, Su L, Rizo J, Liu L, Wang LF, et al. Mixed lineage kinase domain-like protein MLKL causes necrotic membrane disruption upon phosphorylation by RIP3. Mol Cell 2014, 54(1): 133-146.

49. Cai Z, Jitkaew S, Zhao J, Chiang HC, Choksi S, Liu J, et al. Plasma membrane translocation of trimerized MLKL protein is required for TNF-induced necroptosis. Nature cell biology 2014, 16(1): 55-65.

50. Chen X, Li W, Ren J, Huang D, He WT, Song Y, et al. Translocation of mixed lineage kinase domain-like protein to plasma membrane leads to necrotic cell death. Cell research 2014, 24(1): 105-121.

51. Alturki NA, McComb S, Ariana A, Rijal D, Korneluk RG, Sun SC, et al. Triad3a induces the degradation of early necrosome to limit RipK1-dependent cytokine production and necroptosis. Cell Death Dis 2018, 9(6): 592.

52. Simpson DS, Gabrielyan A, Feltham R. RIPK1 ubiquitination: Evidence, correlations and the undefined. Semin Cell Dev Biol 2020. 
53. Newton K, Wickliffe KE, Maltzman A, Dugger DL, Strasser A, Pham VC, et al. RIPK1 inhibits ZBP1-driven necroptosis during development. Nature 2016, 540(7631): 129-133.

54. Hoetelmans RW, Prins FA, Cornelese-ten Velde I, van der Meer J, van de Velde CJ, van Dierendonck JH. Effects of acetone, methanol, or paraformaldehyde on cellular structure, visualized by reflection contrast microscopy and transmission and scanning electron microscopy. Appl Immunohistochem Mol Morphol 2001, 9(4): 346-351.

55. Moloney M, McDonnell L, O'Shea H. Atomic force microscopy of BHK-21 cells: an investigation of cell fixation techniques. Ultramicroscopy 2004, 100(3-4): 153-161.

56. Whelan DR, Bell TD. Correlative Synchrotron Fourier Transform Infrared Spectroscopy and Single Molecule Super Resolution Microscopy for the Detection of Composition and Ultrastructure Alterations in Single Cells. ACS Chem Biol 2015, 10(12): 2874-2883.

57. Xu X, Kalac M, Markson M, Chan M, Brody JD, Bhagat G, et al. Reversal of CYLD phosphorylation as a novel therapeutic approach for adult T-cell leukemia/lymphoma (ATLL). Cell Death Dis 2020, 11(2): 94.

58. Yang C, Li J, Yu L, Zhang Z, Xu F, Jiang L, et al. Regulation of RIP3 by the transcription factor Sp1 and the epigenetic regulator UHRF1 modulates cancer cell necroptosis. Cell Death Dis 2017, 8(10): e3084.

59. Wang S, Ni HM, Dorko K, Kumer SC, Schmitt TM, Nawabi A, et al. Increased hepatic receptor interacting protein kinase 3 expression due to impaired proteasomal functions contributes to alcohol-induced steatosis and liver injury. Oncotarget 2016, 7(14): 1768117698.

60. Zhang S, Che L, He C, Huang J, Guo N, Shi J, et al. Drp1 and RB interaction to mediate mitochondria-dependent necroptosis induced by cadmium in hepatocytes. Cell Death Dis 2019, 10(7): 523 .

61. Ali M, Mocarski ES. Proteasome inhibition blocks necroptosis by attenuating death complex aggregation. Cell Death Dis 2018, 9(3): 346. 
62. Gong YN, Guy C, Olauson H, Becker JU, Yang M, Fitzgerald P, et al. ESCRT-III Acts Downstream of MLKL to Regulate Necroptotic Cell Death and Its Consequences. Cell 2017, 169(2): 286-300 e216.

63. Yoon S, Bogdanov K, Kovalenko A, Wallach D. Necroptosis is preceded by nuclear translocation of the signaling proteins that induce it. Cell Death Differ 2016, 23(2): 253-260.

64. Wang Z, Jiang H, Chen S, Du F, Wang X. The mitochondrial phosphatase PGAM5 functions at the convergence point of multiple necrotic death pathways. Cell 2012, 148(1-2): 228-243.

65. Mizumura K, Cloonan SM, Nakahira K, Bhashyam AR, Cervo M, Kitada T, et al. Mitophagydependent necroptosis contributes to the pathogenesis of COPD. J Clin Invest 2014, 124(9):

66. Samson AL, Garnish SE, Hildebrand JM, Murphy JM. Location, location, location: a compartmentalized view of necroptotic signaling. Under review.

67. Tanzer MC, Khan N, Rickard JA, Etemadi N, Lalaoui N, Spall SK, et al. Combination of IAP antagonist and IFNgamma activates novel caspase-10- and RIPK1-dependent cell death

68. Newton K, Sun X, Dixit VM. Kinase RIP3 is dispensable for normal NF-kappa Bs, signaling by the B-cell and T-cell receptors, tumor necrosis factor receptor 1, and Toll-like receptors 2

69. Bossen C, Ingold K, Tardivel A, Bodmer JL, Gaide O, Hertig S, et al. Interactions of tumor necrosis factor (TNF) and TNF receptor family members in the mouse and human. $J$ Biol Chem 2006, 281(20): 13964-13971.

70. Vince JE, Wong WW, Khan N, Feltham R, Chau D, Ahmed AU, et al. IAP antagonists target cIAP1 to induce TNFalpha-dependent apoptosis. Cell 2007, 131(4): 682-693. 
797 71. Schneider CA, Rasband WS, Eliceiri KW. NIH Image to ImageJ: 25 years of image analysis. 798 Nat Methods 2012, 9(7): 671-675.

799

800 
bioRxiv preprint doi: https://doi.org/10.1101/2020.10.26.356063; this version posted October 26, 2020. The copyright holder for this

preprint (which was not certified by peer review) is the author/funder, who has granted bioRxiv a license to display the preprint in perpetuity. It is made available under aCC-BY-ND 4.0 International license.

Figure 1
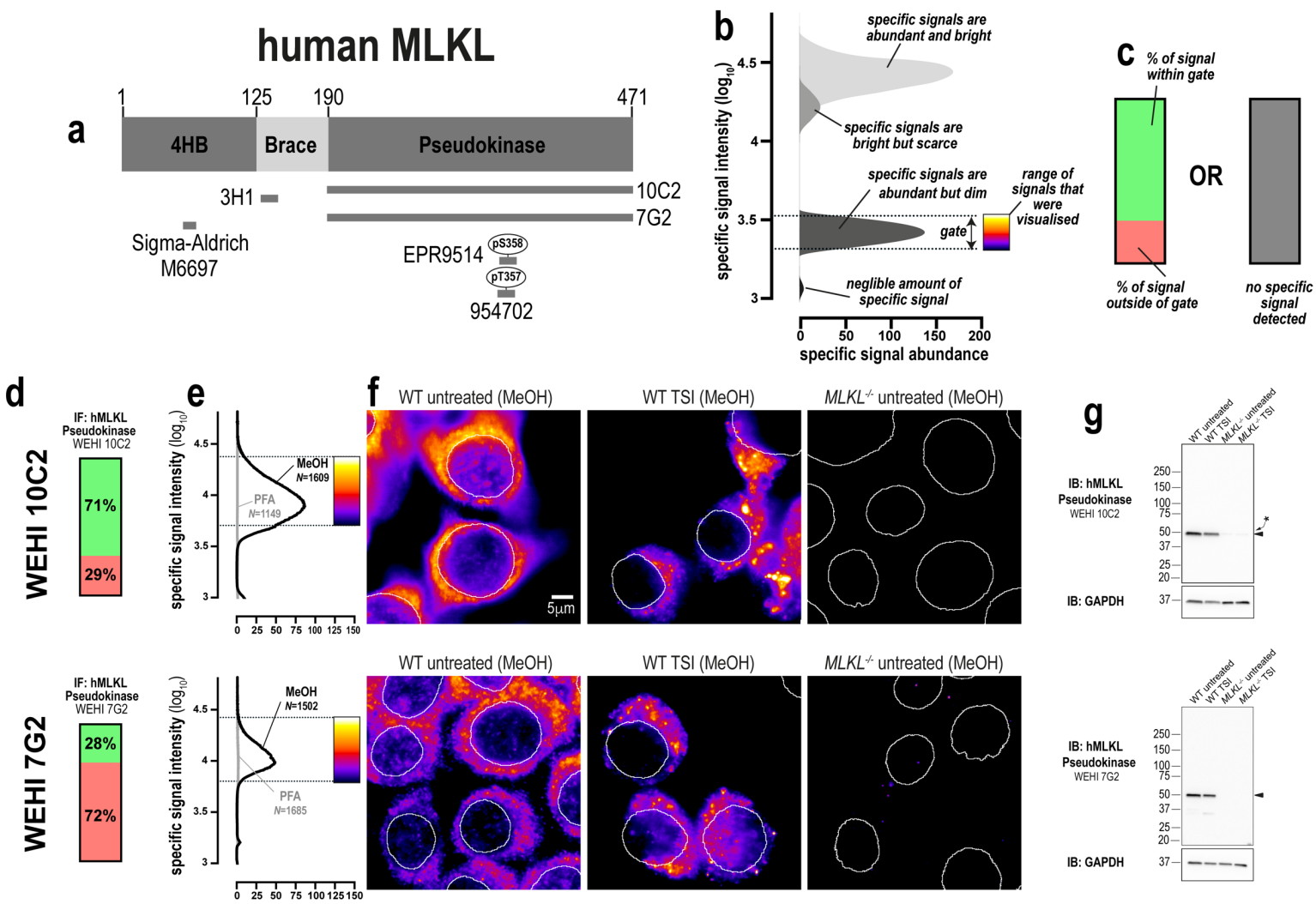

MLKL untreated $(\mathrm{MeOH})$
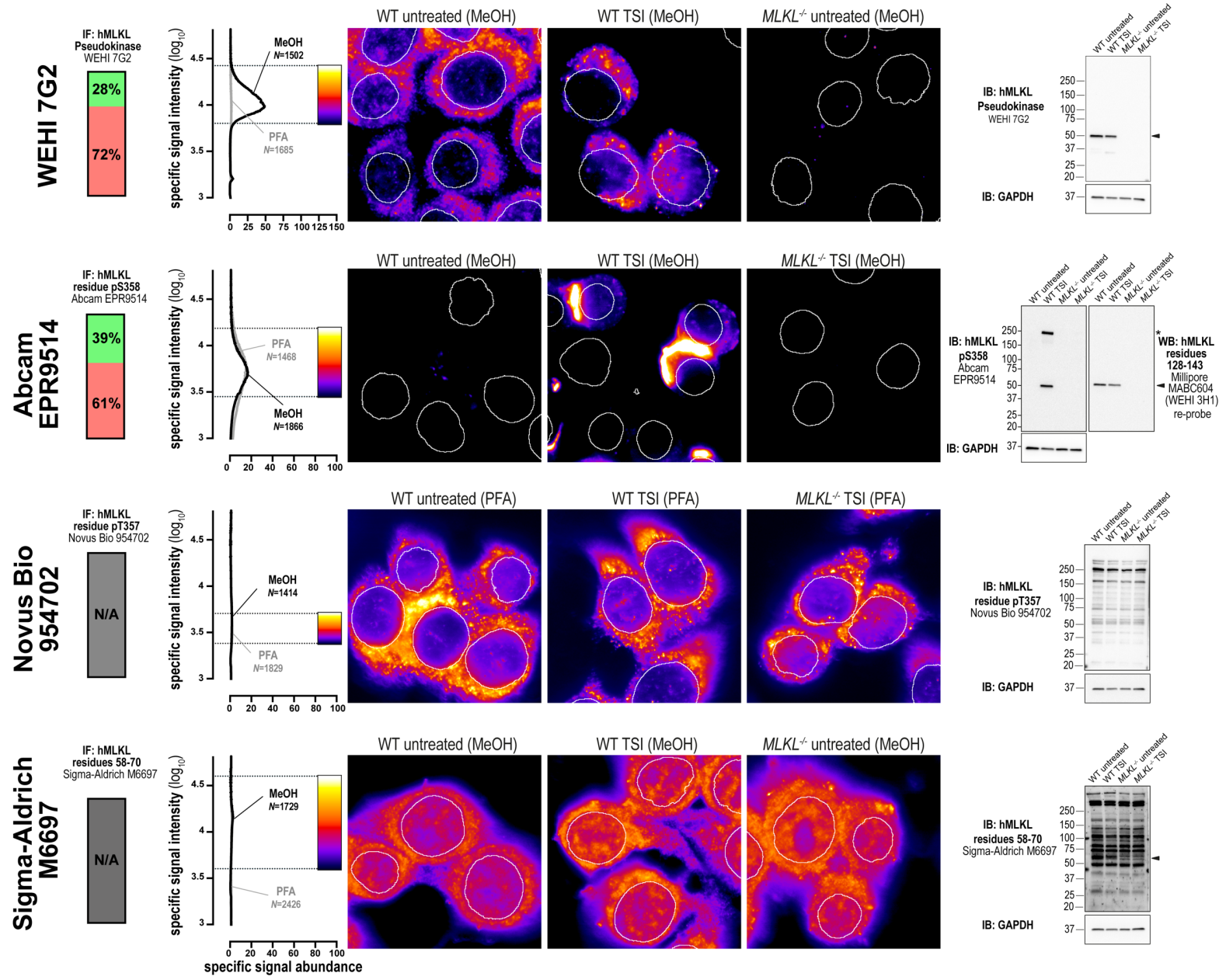
Figure 1: Methanol fixation is optimal for the immunofluorescent detection of human MLKL

a Human MLKL domain architecture showing the immunogens used to raise the tested anti-MLKL antibodies. b Demonstration of how signal-to-noise ratios were used to quantify the abundance and brightness of specific immunofluorescent signals generated by different antibodies. The $5^{\text {th }}$ and $95^{\text {th }}$

807 percentile of each signal-to-noise curve defines the gate where specific immunosignals were observed. As indicated by the pseudocolour look-up-table, only immunosignals within this gate were visualised. c Chart exemplifying how the amount of signal within the gate, relative to the total amount of detectable signal, provides another gauge of antibody specificity for immunofluorescence. d

811 Quantitation of the percentage of gated signals for the tested MLKL antibodies. e Quantitation of 812 specific signal abundance produced by the tested MLKL antibodies on methanol-fixed (MeOH) or 813 paraformaldehyde-fixed (PFA) HT29 cells. The number of cells imaged (N) to generate each signal814 to-noise curve is shown. $\mathbf{f}$ Micrographs of immunofluorescent signals for the tested MLKL antibodies 815 on HT29 cells. As indicated by each pseudocolour look-up-table, only immunosignals within the 816 respective gate in panel e were visualised. Data are representative of $n=3$ (clones 10C2, 7G2) and $817 \mathrm{n}=2$ (Abcam clone EPR9514, Novus Biological MAB9187/clone 954702 and Sigma-Aldrich M6697) 818 independent experiments. Nuclei were detected by Hoechst 33342 staining and are demarked by 819 white outlines in micrographs. $\mathrm{g}$ Immunoblot using the tested MLKL antibodies against wild-type 820 and $M L K L^{-/-}$HT29 cell lysates. Closed arrowheads indicate the main specific band. Asterisks indicate 821 non-specific bands that could otherwise confound data interpretation. Immunoblots were re-probed 822 for GAPDH as loading control. 
bioRxiv preprint doi: https://doi.org/10.1101/2020.10.26.356063; this version posted October 26, 2020. The copyright holder for this preprint (which was not certified by peer review) is the author/funder, who has granted bioRxiv a license to display the preprint in perpetuity. It is made available under aCC-BY-ND 4.0 International license.

\section{Figure 2}

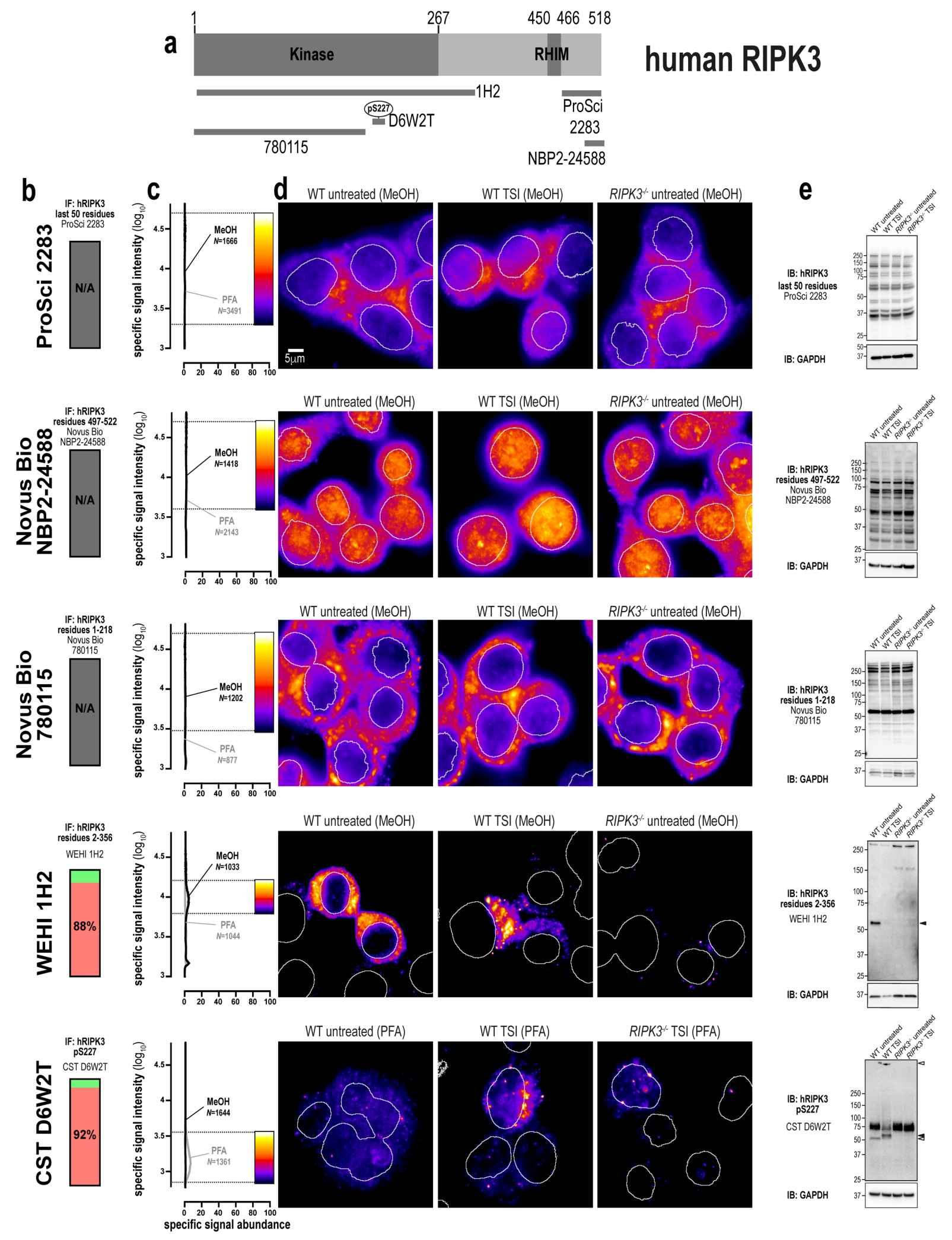


Figure 2: Better antibodies are needed for imaging human RIPK3.

827 a Human RIPK3 domain architecture showing the immunogens or epitopes for the tested anti-RIPK3 828 antibodies. b Quantitation of the percentage of gated signals for the tested RIPK3 antibodies. c 829 Quantitation of specific signal abundance produced by the tested RIPK3 antibodies on methanol830 fixed $(\mathrm{MeOH})$ or paraformaldehyde-fixed (PFA) HT29 cells. The number of cells imaged (N) to 831 generate each signal-to-noise curve is shown. d Micrographs of immunofluorescent signals for the 832 tested RIPK3 antibodies on HT29 cells. As indicated by each pseudocolour look-up-table, only 833 immunosignals within the respective gate in panel $\mathbf{c}$ were visualised. Data are representative of $n=3$ 834 (Cell Signaling Technology clone D6W2T and in-house clone 1H2) and n=2 (ProSci 2283, Novus 835 Biological NBP2-24588 and MAB7604/clone 780115) independent experiments. Nuclei were 836 detected by Hoechst 33342 staining and are demarked by white outlines in micrographs. e 837 Immunoblot using the tested RIPK3 antibodies against wild-type and RIPK3 ${ }^{-/}$HT29 cell lysates. 838 Closed arrowheads indicate the main specific band. Open arrowheads indicate other specific bands 839 of interest. Immunoblots were re-probed for GAPDH as loading control. 


\section{Figure 3}
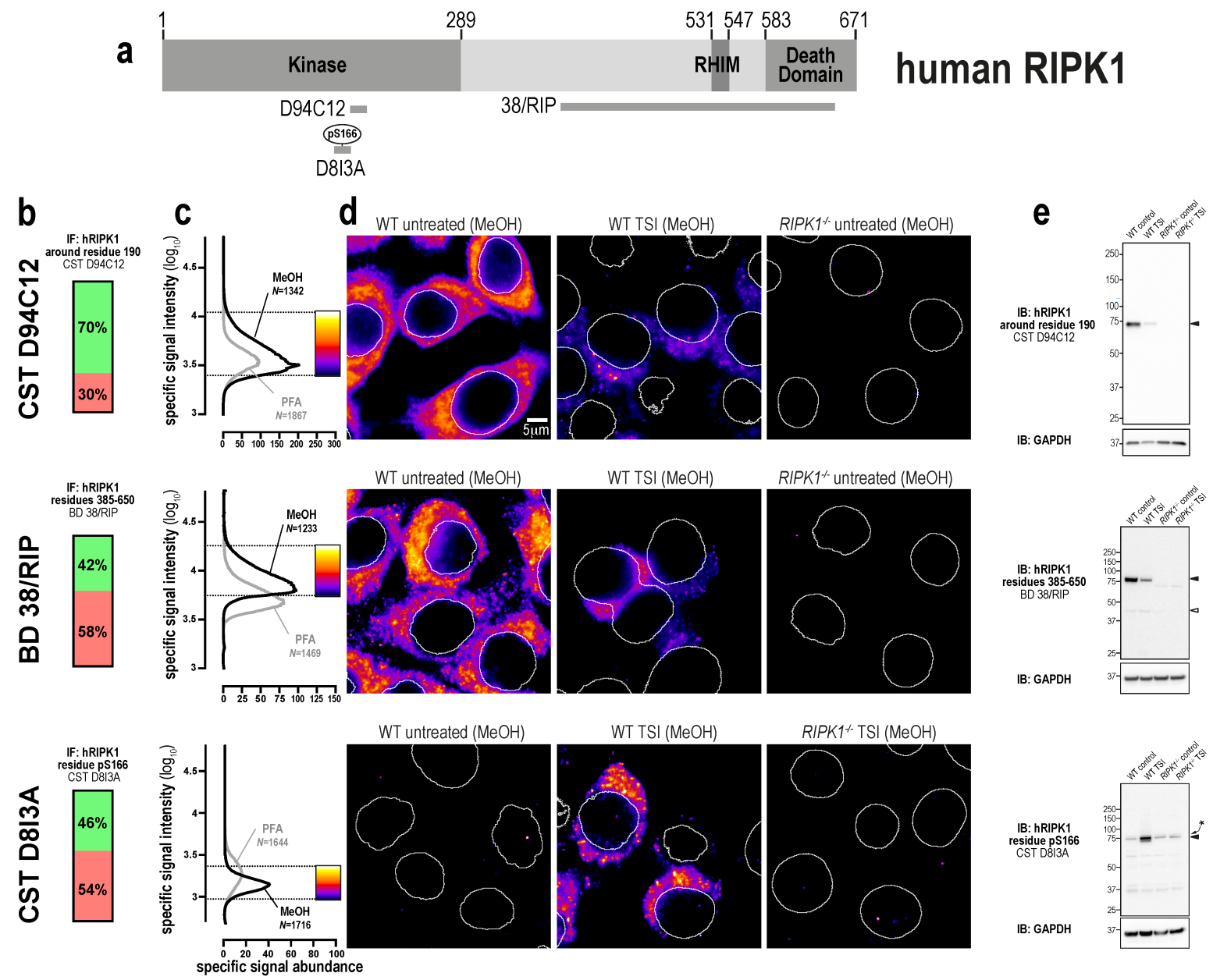

Figure 3: Three specific antibodies for imaging endogenous human RIPK1.

844 a Human RIPK1 domain architecture showing the immunogens or epitopes for the tested anti-RIPK1 845 antibodies. b Quantitation of the percentage of gated signals for the tested RIPK1 antibodies. c 846 Quantitation of specific signal abundance produced by the tested RIPK1 antibodies on methanol847 fixed $(\mathrm{MeOH})$ or paraformaldehyde-fixed (PFA) HT29 cells. The number of cells imaged (N) to 848 generate each signal-to-noise curve is shown. d Micrographs of immunofluorescent signals for the 849 tested RIPK1 antibodies on HT29 cells. As indicated by each pseudocolour look-up-table, only 850 immunosignals within the respective gate in panel $\mathbf{c}$ were visualised. Data are representative of $n=2$ 851 (Cell Signaling Technology clones D94C12 and D8I3A, BD Transduction laboratories clone 38/RIP) 852 independent experiments. Nuclei were detected by Hoechst 33342 staining and are demarked by 
853 white outlines in micrographs. e Immunoblot using the tested RIPK1 antibodies against wild-type 854 and $R I P K 1^{-/-}$HT29 cell lysates. Closed arrowheads indicate the main specific band. Open arrowheads 855 indicate other specific bands of interest. Asterisks indicate non-specific bands that could otherwise 856 confound data interpretation. Immunoblots were re-probed for GAPDH as loading control.

857

858 


\section{Figure 4}

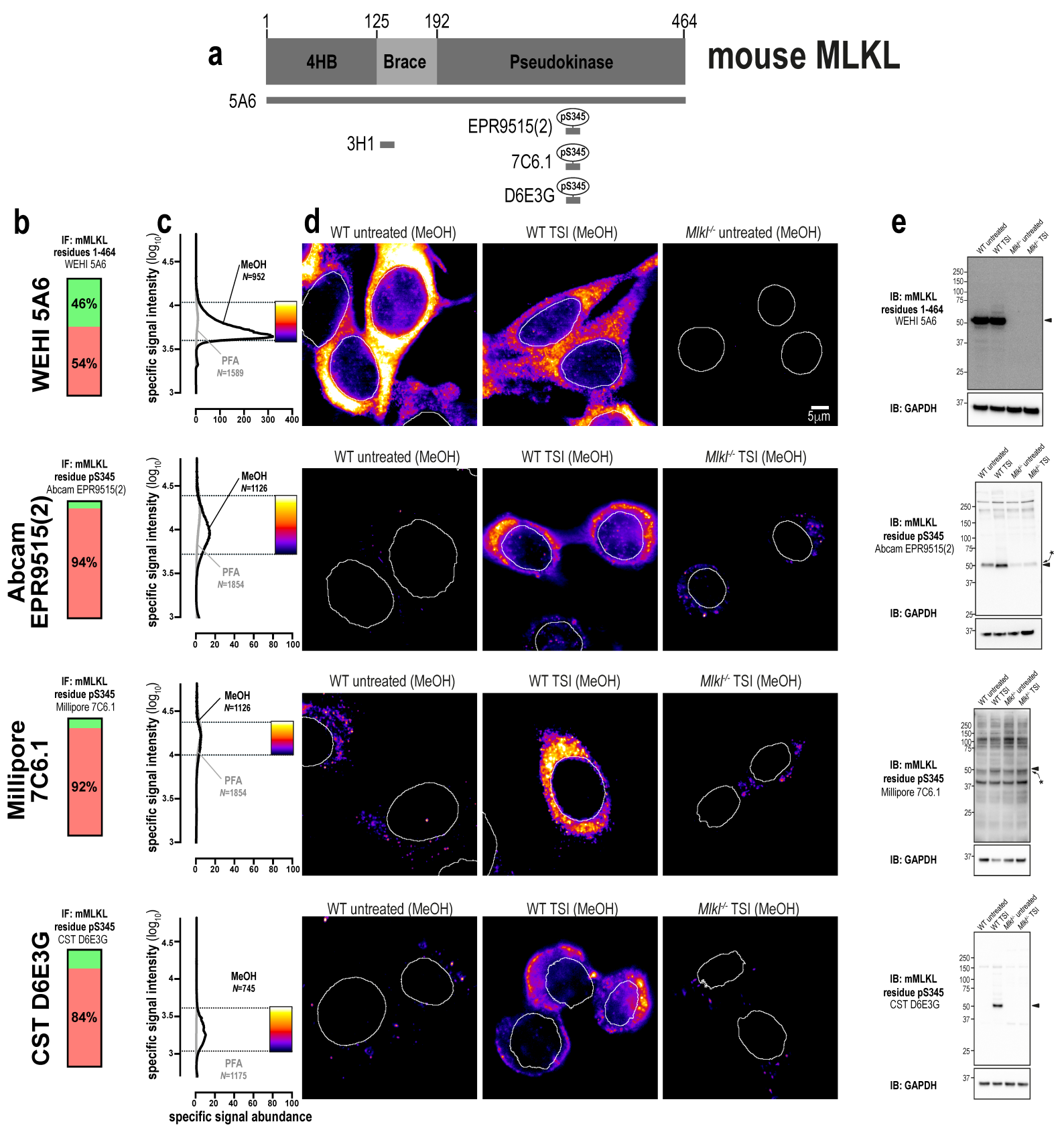

860 Figure 4: A new monoclonal antibody to image endogenous mouse MLKL.

861 a Mouse MLKL domain architecture showing the immunogens or epitopes for the tested anti-MLKL 862 antibodies. b Quantitation of the percentage of gated signals for the tested MLKL antibodies. c 863 Quantitation of specific signal abundance produced by the tested MLKL antibodies on methanol864 fixed (MeOH) or paraformaldehyde-fixed (PFA) MDFs. The number of cells imaged (N) to generate each signal-to-noise curve is shown. d Micrographs of immunofluorescent signals for the tested 
866 MLKL antibodies on MDFs. As indicated by each pseudocolour look-up-table, only immunosignals 867 within the respective gate in panel $\mathbf{c}$ were visualised. Data are representative of $n=3$ (in-house clone 868 5A6) and $n=2$ (Abcam clone EPR9515(2), Millipore MABC1158/clone 7C6.1 and Cell Signaling 869 Technology clone D6E3G) independent experiments. Nuclei were detected by Hoechst 33342 870 staining and are demarked by white outlines in micrographs. e Immunoblot using the tested MLKL 871 antibodies against lysates from wild-type and $\mathrm{Mlkl}^{--}$MDFs. Closed arrowheads indicate the main 872 specific band. Asterisks indicate non-specific bands that could otherwise confound data 873 interpretation. Immunoblots were re-probed for GAPDH as loading control. 
Figure 5

a
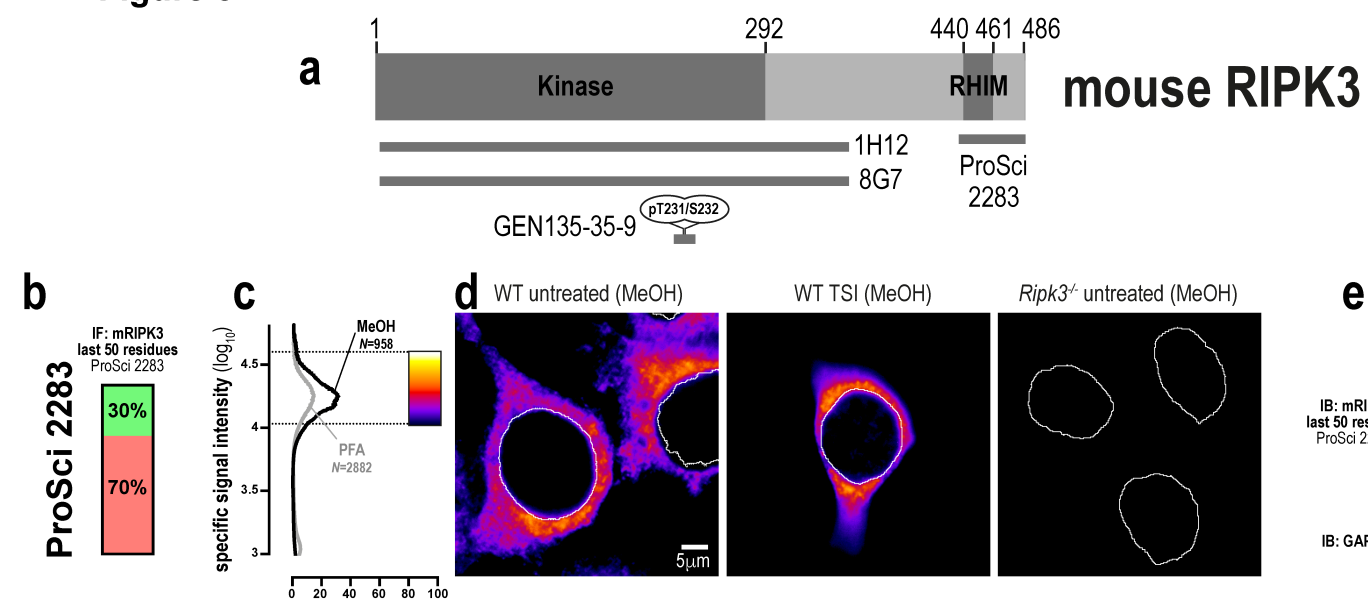

d WT untreated $(\mathrm{MeOH})$

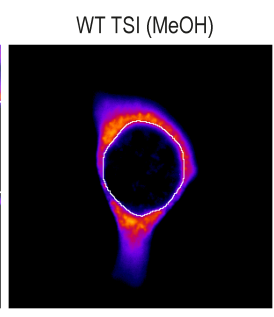

Ripk3- untreated (MeOH)
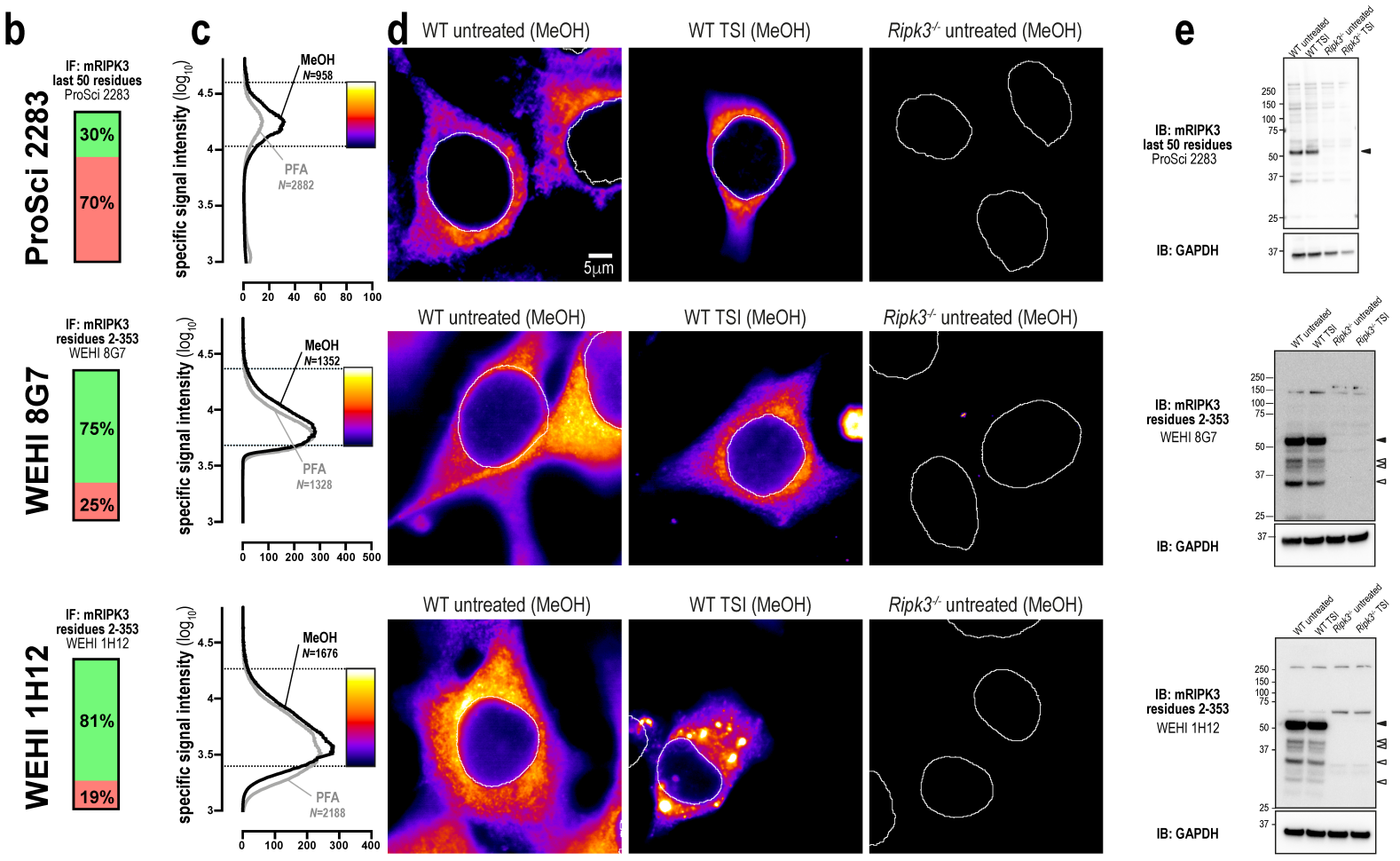

Ripk3\% untreated $(\mathrm{MeOH})$
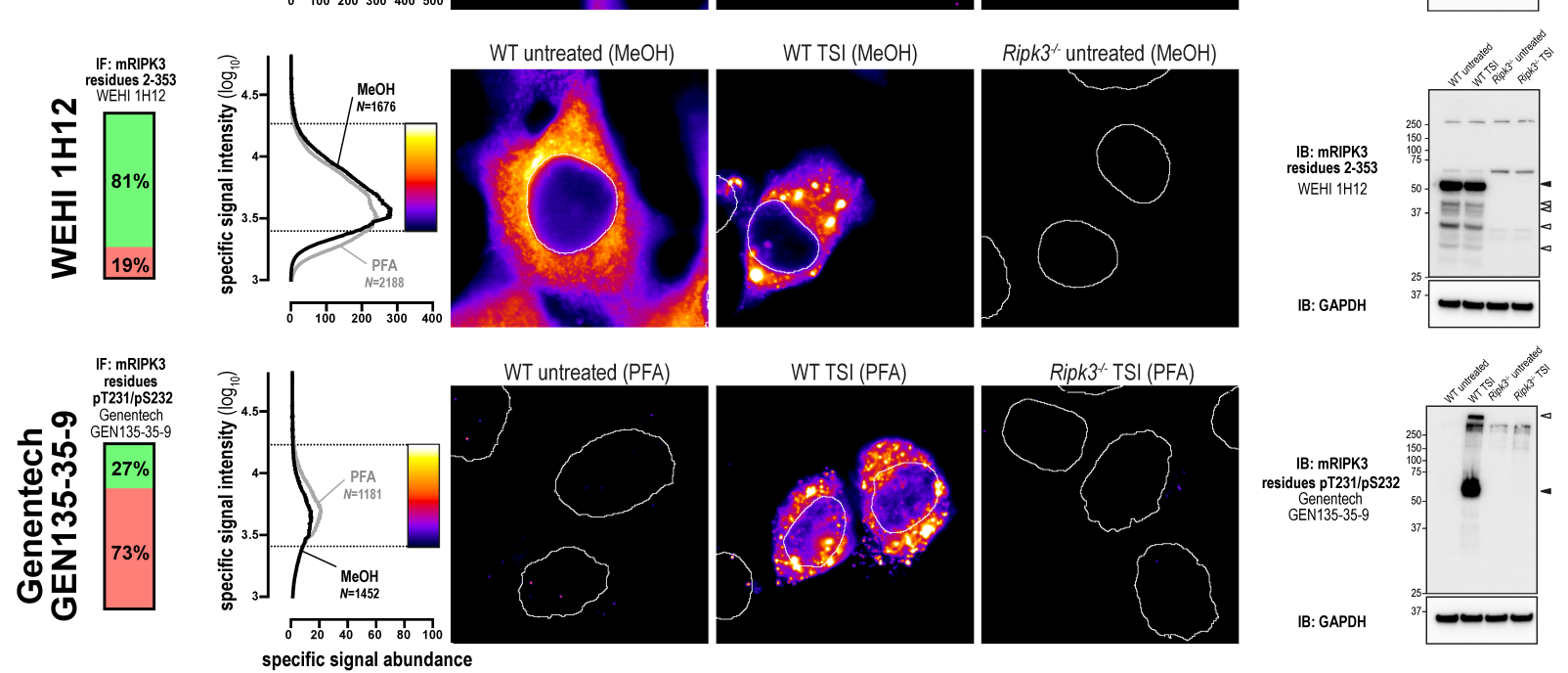

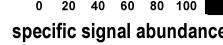

Figure 5: Unlike human RIPK3, mouse RIPK3 is highly amenable to detection by

\section{immunofluorescence and immunoblotting.}

879 a Mouse RIPK3 domain architecture showing the immunogens or epitopes for the tested anti-RIPK3 880 antibodies. b Quantitation of the percentage of gated signals for the tested RIPK3 antibodies. c 881 Quantitation of specific signal abundance produced by the tested RIPK3 antibodies on methanol882 fixed $(\mathrm{MeOH})$ or paraformaldehyde-fixed (PFA) MDFs. The number of cells imaged (N) to generate 883 each signal-to-noise curve is shown. d Micrographs of immunofluorescent signals for the tested 
884 RIPK3 antibodies on MDFs. As indicated by each pseudocolour look-up-table, only immunosignals 885 within the respective gate in panel $\mathbf{c}$ were visualised. Data are representative of $n=3$ (in-house clone 8868 G7 and Genentech clone GEN135-35-9) and n=2 (ProSci 2283, in-house clone 1H12) independent 887 experiments. Nuclei were detected by Hoechst 33342 staining and are demarked by white outlines in 888 micrographs. e Immunoblot using the tested RIPK3 antibodies against lysates from wild-type and 889 Ripk3 ${ }^{-/}$MDFs. Closed arrowheads indicate the main specific band. Open arrowheads indicate other 890 specific bands of interest. Immunoblots were re-probed for GAPDH as loading control. 
Figure 6

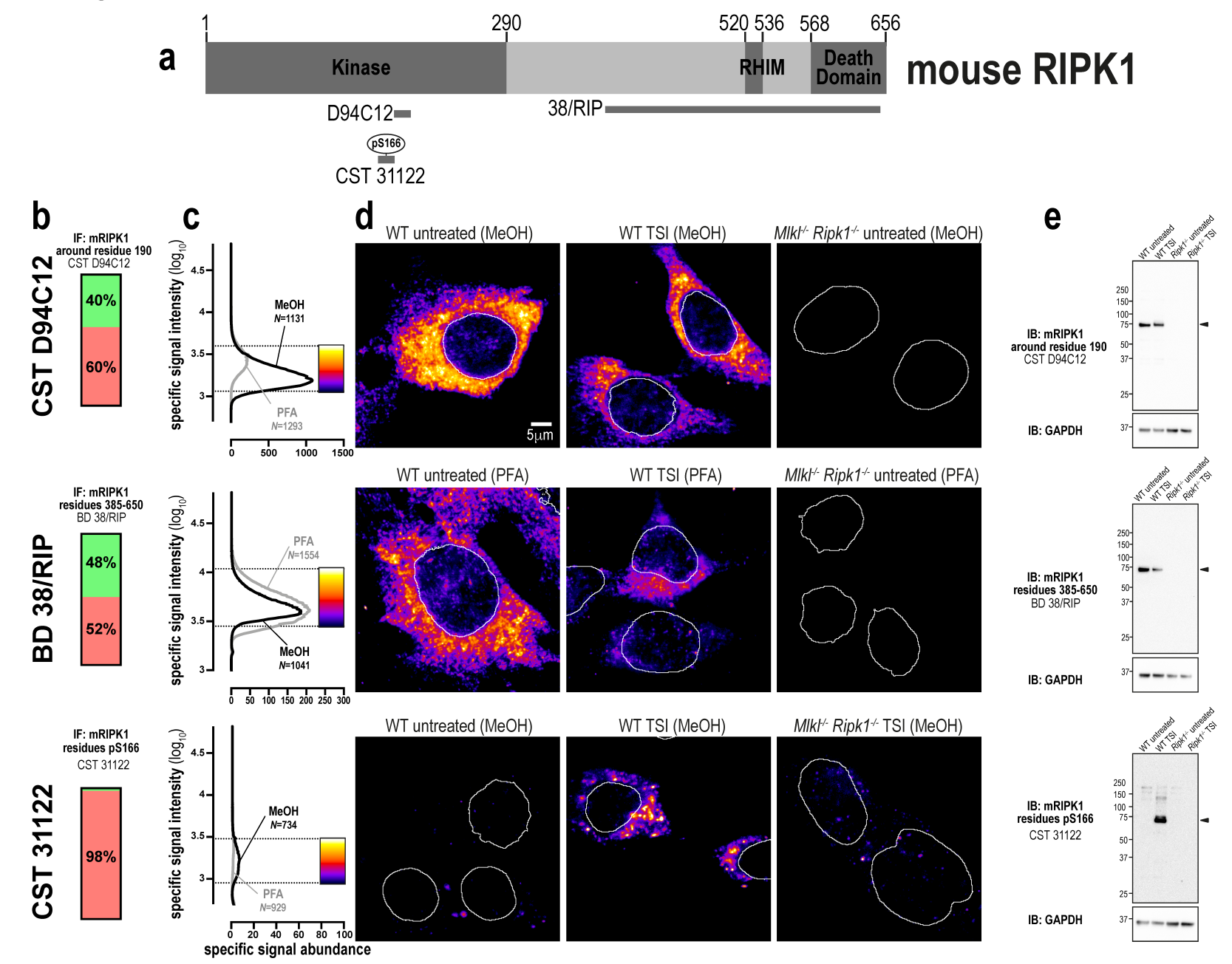

Figure 6: Three specific antibodies for imaging endogenous mouse RIPK1.

895 a Mouse RIPK1 domain architecture showing the immunogens or epitopes for the tested anti-RIPK1

896 antibodies. b Quantitation of the percentage of gated signals for the tested RIPK1 antibodies. c

897 Quantitation of specific signal abundance produced by the tested RIPK1 antibodies on methanol-

898 fixed $(\mathrm{MeOH})$ or paraformaldehyde-fixed (PFA) MDFs. The number of cells imaged $(\mathrm{N})$ to generate

899 each signal-to-noise curve is shown. d Micrographs of immunofluorescent signals for the tested

900 RIPK1 antibodies on MDFs. As indicated by each pseudocolour look-up-table, only immunosignals

901 within the respective gate in panel $\mathbf{c}$ were visualised. Data are representative of $n=2$ (Cell Signaling

902 Technology clones D94C12 and 31122, and BD Transduction Laboratories clone 38/RIP)

903 independent experiments. Nuclei were detected by Hoechst 33342 staining and are demarked by 
904 white outlines in micrographs. e Immunoblot using the tested RIPK1 antibodies against lysates from 905 wild-type and Ripk1 $1^{-/}$MDFs. Closed arrowheads indicate the main specific band. Open arrowheads 906 indicate other specific bands of interest. Immunoblots were re-probed for GAPDH as loading control. 907 908 
bioRxiv preprint doi: https://doi.org/10.1101/2020 10.26.356063; this version posted October 26, 2020. The copyright holder for this preprint (which was not certified by peer review) is the author/funder, who has granted bioRxiv a license to display the preprint in perpetuity. It is made available under aCC-BY-ND 4.0 International license.

\section{Figure 7}

a

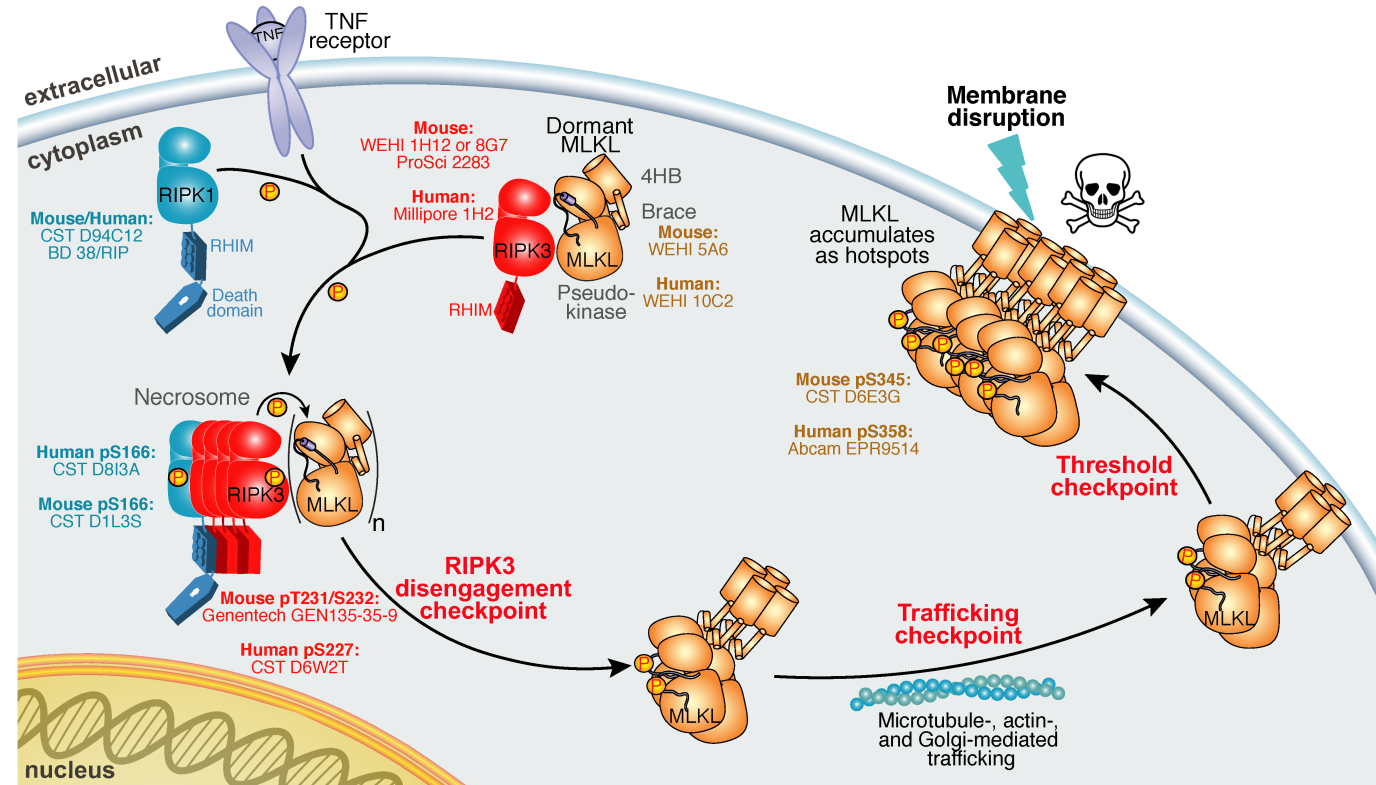

b

\begin{tabular}{|c|c|c|c|c|c|}
\hline & \multicolumn{3}{|c|}{ mouse cells } & \multicolumn{2}{|c|}{ human cells } \\
\hline & cocktail \#1 & cocktail \#2 & cocktail \#3 & cocktail \#4 & cocktail \#5 \\
\hline $\begin{array}{c}\text { channel \#1 } \\
\text { (detected with fluorescent } \\
\text { anti-rat IgG) }\end{array}$ & $\begin{array}{l}\text { MLKL (clone } 5 \mathrm{A6} \text { ) or } \\
\text { RIPK3 (clone } \\
8 \mathrm{G} 7 / 1 \mathrm{H} 12 \text { ) }\end{array}$ & $\begin{array}{l}\text { MLKL (clone } 5 A 6 \text { ) or } \\
\text { RIPK3 (clone } \\
8 \mathrm{G} 7 / 1 \mathrm{H} 12 \text { ) }\end{array}$ & $\begin{array}{l}\text { MLKL (clone } 5 \mathrm{A6} \text { ) or } \\
\text { RIPK3 (clone } \\
8 \mathrm{G} 7 / 1 \mathrm{H} 12 \text { ) }\end{array}$ & $\begin{array}{l}\text { MLKL (clone 10C2) or } \\
\text { RIPK3 (clone 1H2) }\end{array}$ & $\begin{array}{l}\text { MLKL (clone 10C2) } \\
\text { or RIPK3 (clone } 1 \mathrm{H} 2 \text { ) }\end{array}$ \\
\hline $\begin{array}{c}\text { channel \#2 } \\
\text { (detected with fluorescent } \\
\text { anti-rabbit } \mid \mathrm{g} G \text { ) }\end{array}$ & $\begin{array}{l}\text { phospho-MLKL } \\
\text { (clone D6E3G) }\end{array}$ & $\begin{array}{c}\text { phospho-RIPK3 } \\
\text { (clone GEN135-35-9) }\end{array}$ & $\begin{array}{l}\text { phospho-RIPK1 } \\
\text { (CST 31122) }\end{array}$ & $\begin{array}{l}\text { phospho-MLKL } \\
\text { (clone EPR9514) }\end{array}$ & $\begin{array}{l}\text { phospho-RIPK1 } \\
\text { (clone D8I3A) }\end{array}$ \\
\hline $\begin{array}{c}\text { channel \#3 } \\
\text { (detected with fluorescent } \\
\text { anti-mouse lgG) }\end{array}$ & $\begin{array}{c}\text { RIPK1 } \\
\text { (clone 38/RIP) }\end{array}$ & $\begin{array}{c}\text { RIPK1 } \\
\text { (clone 38/RIP) }\end{array}$ & $\begin{array}{c}\text { RIPK1 } \\
\text { (clone 38/RIP) }\end{array}$ & $\begin{array}{c}\text { RIPK1 } \\
\text { (clone 38/RIP) }\end{array}$ & $\begin{array}{c}\text { RIPK1 } \\
\text { (clone 38/RIP) }\end{array}$ \\
\hline $\begin{array}{c}\text { channel \#4 } \\
\text { (suggested counterstains) }\end{array}$ & $\begin{array}{l}\text { DNA (Hoechst 33342) } \\
\text { with fluorescent stre } \\
\text { detection with fluoresce }\end{array}$ & $\begin{array}{l}\text { embranes (biotinyl } \\
\text { avidin), microtubul } \\
\text { anti-sheep } \lg G \text { ), or e }\end{array}$ & $\begin{array}{l}\text { wheat germ aggluti } \\
\text { anti-tubulin immuno } \\
\text { endosomes (bioti }\end{array}$ & $\begin{array}{l}\text { added } 10 \text { minutes befor } \\
\text { rescence with Cytoskele } \\
\text { ted transferrin added } 1\end{array}$ & $\begin{array}{l}\text { fixation then detected } \\
\text { on Inc. \# ATN02 then } \\
\text { minutes before fixation }\end{array}$ \\
\hline
\end{tabular}

C
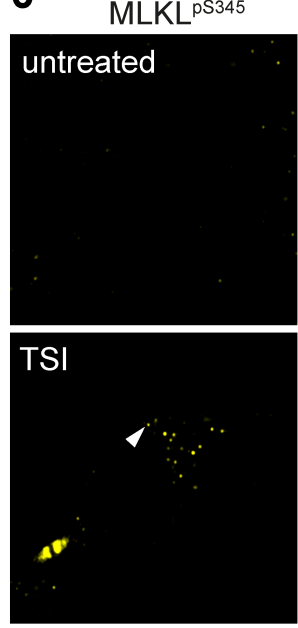

MLKL ${ }^{5 A 6}$
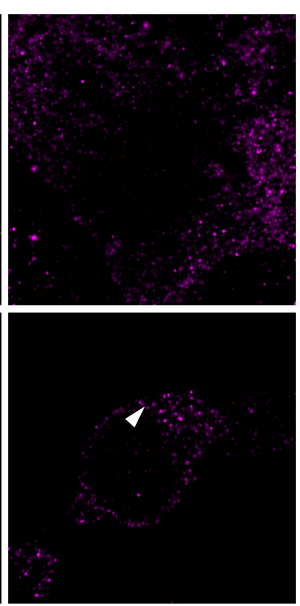
then detected with fluorescent streptavidin)

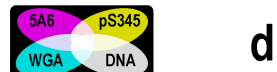
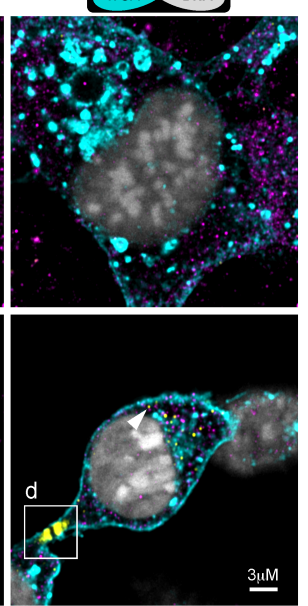

d

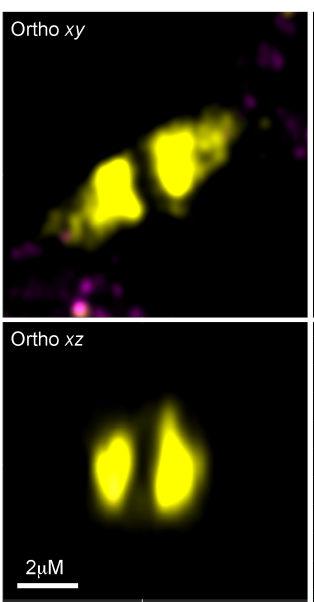

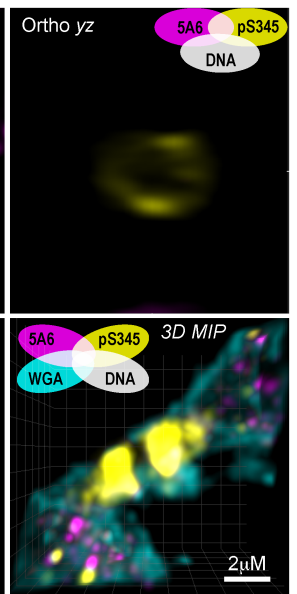

910 Figure 7: Optimised antibody cocktails for visualising endogenous necroptotic signaling in fixed

\section{1 human and mouse cells.}


a Cartoon summary of the currently-understood chronology of TNF-induced necroptosis.

913 Recommendations of validated antibodies for immunostaining various steps in the necroptotic

914 pathway are provided. b Summary of validated antibody cocktails and counterstains that can be 915 multiplexed to examine endogenous necroptotic signaling in fixed human and mouse cells. Successful 916 detection of specific signals relies on fixation in methanol, rather than crosslinking fixatives such as 917 paraformaldehyde. c Two-dimensional Airyscan micrographs of Wheat Germ Agglutinin (WGA)918 stained membranes, Hoechst-stained DNA and anti-MLKL immunosignals from clone 5A6 and clone 919 D6E3G on methanol-fixed wild-type MDFs that had been left untreated or TSI-treated for 60min. 920 Arrowhead exemplifies the small clusters of MLKL that form during necroptosis. The box indicates 921 the junctional accumulation of phospho-MLKL. d Three-dimensional orthogonal projections and 922 maximum intensity projection (MIP) of the boxed region from panel $\mathbf{c}$ showing a ring-like structure 923 adopted by phospho-MLKL at the WGA-stained plasma membrane. Accompanied by Supplementary 924 Video 1. 